\title{
Design Issues of Innovative Furniture Fasteners for Wood-based Boards
}

\author{
Bogdan Branowski, ${ }^{\mathrm{a}}$ Karol Starczewski, ${ }^{\mathrm{a}}$ Marek Zabłocki, ${ }^{\mathrm{b}}$ and Maciej Sydor ${ }^{\mathrm{c}, *}$ \\ A methodical approach to designing new furniture fasteners for \\ lignocellulosic materials will uncover new sources of innovation. This \\ paper presents an example of such a design procedure and its results. \\ The outcomes are new concepts of mechanical fasteners for wood-based \\ boards used in frameless furniture. At first, the requirements based on the \\ furniture users, furniture manufacturers, and fastener manufacturers \\ viewpoints were identified. These design criteria were analyzed, and as a \\ result, seven ideas of fasteners with innovative features were created. The \\ invented fasteners provided a starting point to generate prototypes. The \\ prototypes were subjected to multi-dimensional methodical developed \\ evaluations. The purpose of this paper is a detailed presentation of the \\ pathway leading to solutions that are potentially beneficial in terms of \\ product performance and of the identified design limitations. Two main \\ conclusions were made. First, all mechanical furniture fasteners always \\ are a combination of two functional subsystems, anchoring and drive. \\ Secondly, there are a limited number of their design solutions. Despite the \\ wide variety of market offerings, only four anchoring methods are used, \\ and only two drive methods are used in all fasteners.
}

\begin{abstract}
Keywords: Furniture; Design procedure; Design strategy; Engineering design; Furniture fasteners; Woodbased boards

Contact information: a: Digitouch sp. z o.o., ul. Różana 6, 62-002 Suchy Las, Poland; b: Faculty of Transport Engineering, Poznan University of Technology, ul. Piotrowo 3, 60-965 Poznań, Poland; c: Faculty of Forestry and Wood Technology, Poznań University of Life Sciences, ul. Wojska Polskiego 28;

* Corresponding author: maciej.sydor@up.poznan.pl
\end{abstract}

\section{INTRODUCTION}

Furniture fasteners should contain joints with features that are beneficial to furniture users and manufacturers. A furniture user expects aesthetics values, functionality, and reliability, while a manufacturer expects low cost of manufacture, the versatility of application, load capacity, durability, and easy installation (Eckelman 1978; Bartashevich and Trofimov 2006; Smardzewski 2015; Podskarbi et al. 2016; Hitka et al. 2018; Langova et al. 2019; Máchová et al. 2019). The complex load in combination with the specific material properties of wood-based boards results in semi-rigid characteristic of furniture joints in frameless furniture (Joščák 2000; Branowski and Pohl 2004; Joščák and Langová 2018). A furniture joint fastener is usually loaded with internal forces (assembly clamping force $-F_{\text {as}}$ ) and with external forces (Fig. 1). Analytical modelling of the effects of these loads is rendered difficult by the diverse and time-variable strength characteristics of wood materials as well as the presence of co-existing pin joints, glued joints, and joints between the rear wall and the furniture body. A typical approach for obtaining the structural dimensions of furniture joints is the description of the structural properties of the connection using an experimentally determined relationship between the angle of relative 
rotation of the joined elements $(\Theta)$ and the bending moment $(M)$ or the load force $(F)$. This makes it possible to determine the actual load capacity and stiffness of a furniture structural node. The issues related to experimental studies and theoretical modelling of joint with fasteners in frameless furniture applications have been described in literature (Branowski and Pohl 2004; Sydor 2005; Smardzewski et al. 2016).

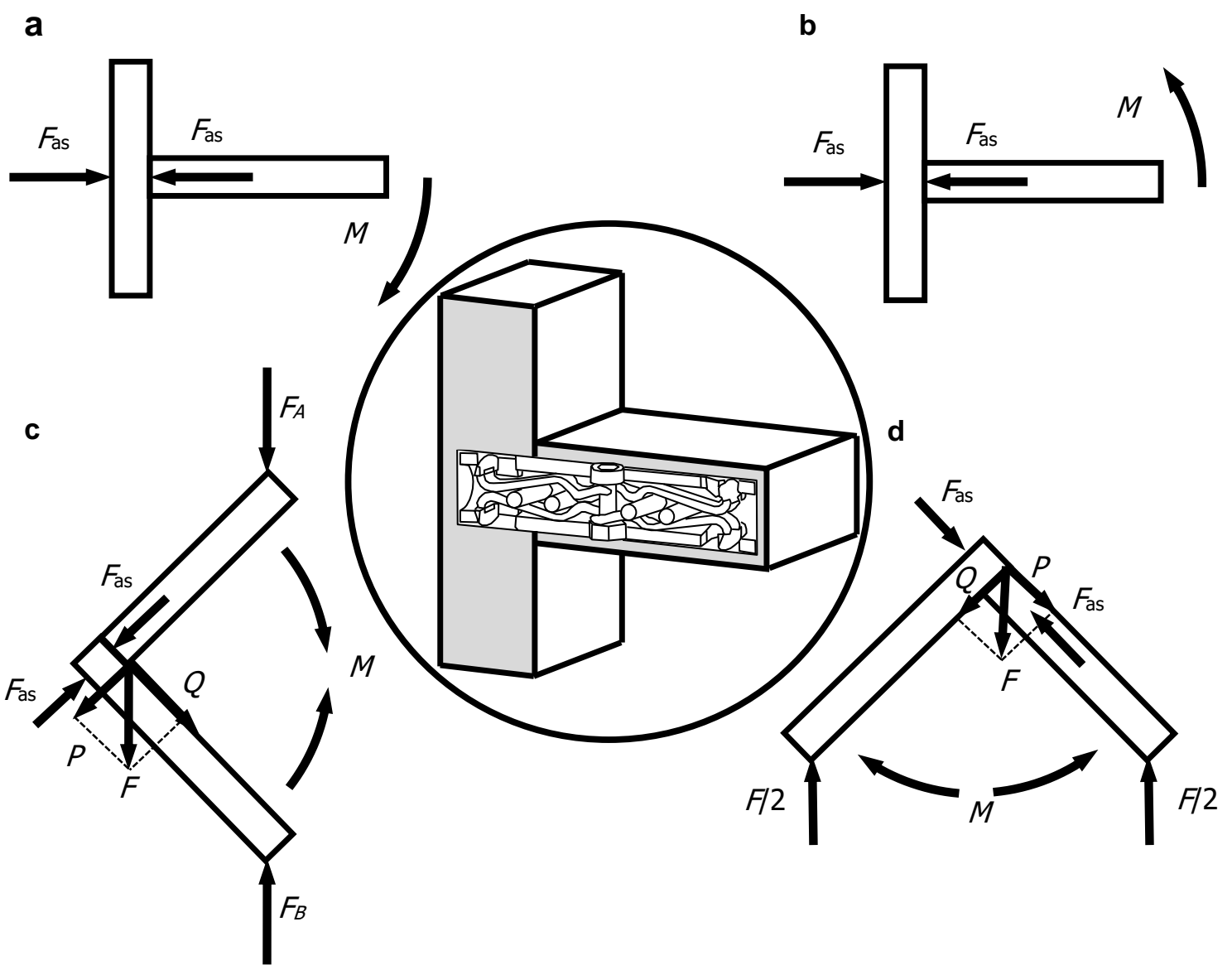

Fig. 1. Furniture joint with typical load patterns $\left(M\right.$ - external bending moment, $F_{\text {as }}$ - assembly clamping force, $Q$ - shear force, $P$ - plane force): $a$ and b - uniaxial stress; c and d - multiaxial stress

The specific design features of each furniture joint therefore depend on many variable factors. These features are determined by the material and geometric properties of the joined elements, the material and geometric properties of the fasteners, and the mounting sockets present in the joined components. The features also depend on the course of the assembly process; they can vary in time depending on the conditions of use (relaxation external load, plastic and elastic deformation, changes in ambient temperature and humidity). Expertly designed and correctly manufactured fasteners are a delicate compromise between the technological capabilities of the manufacturer, logistic efficiency in the fastener's distribution, its ease of installation, and the performance of joints made using the fastener.

All relevant information available to the furniture designer is probabilistic (Tarnowski 1997). Consequently, designing a robust product involves making decisions in conditions of uncertainty with serious consequences for error (Asimow 1962). According 
to Taguchi (1993), a robust solution is a cost-effective and effective in use solution, i.e., a poly-optimal solution. One way of avoiding potential errors is to analyse some proven-inuse products with the same function, with respect to the applied detailed engineering design. The analysis can offer grounds for a creative design synthesis producing new, proprietary concepts of furniture joints. All new concepts need, at the pre-implementation stage, a multi-criterial evaluation and a resulting selection of the best designs (Asimow 1962; Branowski 1999; Cross 2008). The article analyses the current state of knowledge on furniture joints and presents the results of own design work aimed at developing new furniture fasteners with favorable performance features.

\section{IDENTIFICATION OF PROBLEMS IN THE DESIGN OF FURNITURE FASTENERS}

\section{Analysing the Engineering Structure of Furniture Fasteners}

The primary technical function of the furniture fasteners "TO CONNECT" can be broken down into a structure of several partial functions: "TO SET" the position of the joined board components of the furniture $\rightarrow$ "TO TENSION" the elements $\rightarrow$ "TO TRANSFER" the forces $\rightarrow$ "TO ENSURE" the rigidity and load capacity of the furniture under variable conditions $\rightarrow$ "TO DISCONNECT" the connection.

Table 1. Structural Decomposition of Furniture Fasteners

\begin{tabular}{|l|l|l|l|l|}
\hline \multicolumn{5}{|c|}{ Fastening to the furniture components (fastener anchoring method) } \\
\hline Direct & $\begin{array}{l}\text { Screwed in } \\
\text { (Fig. 2c, 2e) }\end{array}$ & Nailed & Glued & $\begin{array}{l}\text { Other (e.g. a } \\
\text { combination of } \\
\text { several } \\
\text { methods) }\end{array}$ \\
\hline $\begin{array}{l}\text { Indirect (with a } \\
\text { coupler) }\end{array}$ & $\begin{array}{l}\text { Screwed in } \\
\text { elastic muff } \\
\text { (Fig. 2a) }\end{array}$ & $\begin{array}{l}\text { Screwed in rigid } \\
\text { muff (Fig. 2b) }\end{array}$ & $\begin{array}{l}\text { Screwed in } \\
\text { expanding muff (Fig. } \\
\text { 2d, 2f, 2g, 2h) }\end{array}$ & Other \\
\hline \multicolumn{1}{|c|}{ Ensuring the assembly clamping force for the joined furniture components (drive) } \\
\hline $\begin{array}{l}\text { Drive with } \\
\text { toothed gear } \\
\text { and crossed } \\
\text { helical gear }\end{array}$ & $\begin{array}{l}\text { Toothed } \\
\text { gear (finger) } \\
\text { (Tab. 2a) }\end{array}$ & $\begin{array}{l}\text { Bevel gear (Tab. } \\
\text { 2b) }\end{array}$ & $\begin{array}{l}\text { Worm gear (Tab. } \\
\text { 2c) }\end{array}$ & $\begin{array}{l}\text { Rack and pinion } \\
\text { gear (Tab. 2d) }\end{array}$ \\
\hline $\begin{array}{l}\text { Drive with } \\
\text { eccentric gear }\end{array}$ & $\begin{array}{l}\text { Single } \\
\text { eccentric } \\
\text { and mandrel } \\
\text { (Fig. 3) }\end{array}$ & $\begin{array}{l}\text { Eccentric wheel - } \\
\text { rack }\end{array}$ & Other & - \\
\hline $\begin{array}{l}\text { Fastening with } \\
\text { a tapered } \\
\text { ferrule }\end{array}$ & Screwed on & $\begin{array}{l}\text { Screwed on and } \\
\text { driven in with one } \\
\text { pin }\end{array}$ & $\begin{array}{l}\text { Screwed on and } \\
\text { driven in with two } \\
\text { pins }\end{array}$ & Other \\
\hline $\begin{array}{l}\text { Drive with } \\
\text { gear (another } \\
\text { principle of } \\
\text { operation) }\end{array}$ & $\begin{array}{l}\text { With two } \\
\text { levers with } \\
\text { plastic } \\
\text { hinges (Fig. } \\
11 \text { ) }\end{array}$ & $\begin{array}{l}\text { With a spring motor } \\
\text { with a percussive } \\
\text { beater drive to } \\
\text { move the } \\
\text { expanding cone } \\
\text { (Fig. 8) }\end{array}$ & $\begin{array}{l}\text { With rotor driven by } \\
\text { magnetic field which } \\
\text { revolves a crossed } \\
\text { helical gear (Fig. 4c) }\end{array}$ & $\begin{array}{l}\text { With a clasp } \\
\text { lock }\end{array}$ \\
\hline
\end{tabular}

The engineering structure of furniture fasteners can be analyzed by considering two primary criteria of classification: the method of fastening to the panels (fastener anchoring 
system) and the method of ensuring the assembly clamping force during the assembly of furniture (fastener drive) (Sydor 2018). The classification is presented in Table 1 and includes two main methods of anchoring the fasteners to the board and four methods ensuring the assembly clamping force between the joined components. It may serve as a basis for listing all the possible solutions in a table, typical for General Morphological Analysis (GMA) developed by Zwicky (1967).

\section{Anchoring the Fastener in the Joined Components}

There is moderate diversity among the fastener anchoring methods; it is possible to use direct fastening (in the form of screwed in, nailed or glued mandrel) or indirect fastening (screwed or nailed in screwed or expanding muff) methods (Table 1). Other anchoring solutions (e.g., glued, directly frictional, shape-frictional (Branowski et al. 2018) or expanding - with catches pulled out from the body when the fastener is closed) are used less often for fastening connectors in the furniture, the most common way to anchor the furniture fastener is to use a thread (Sydor 2019).
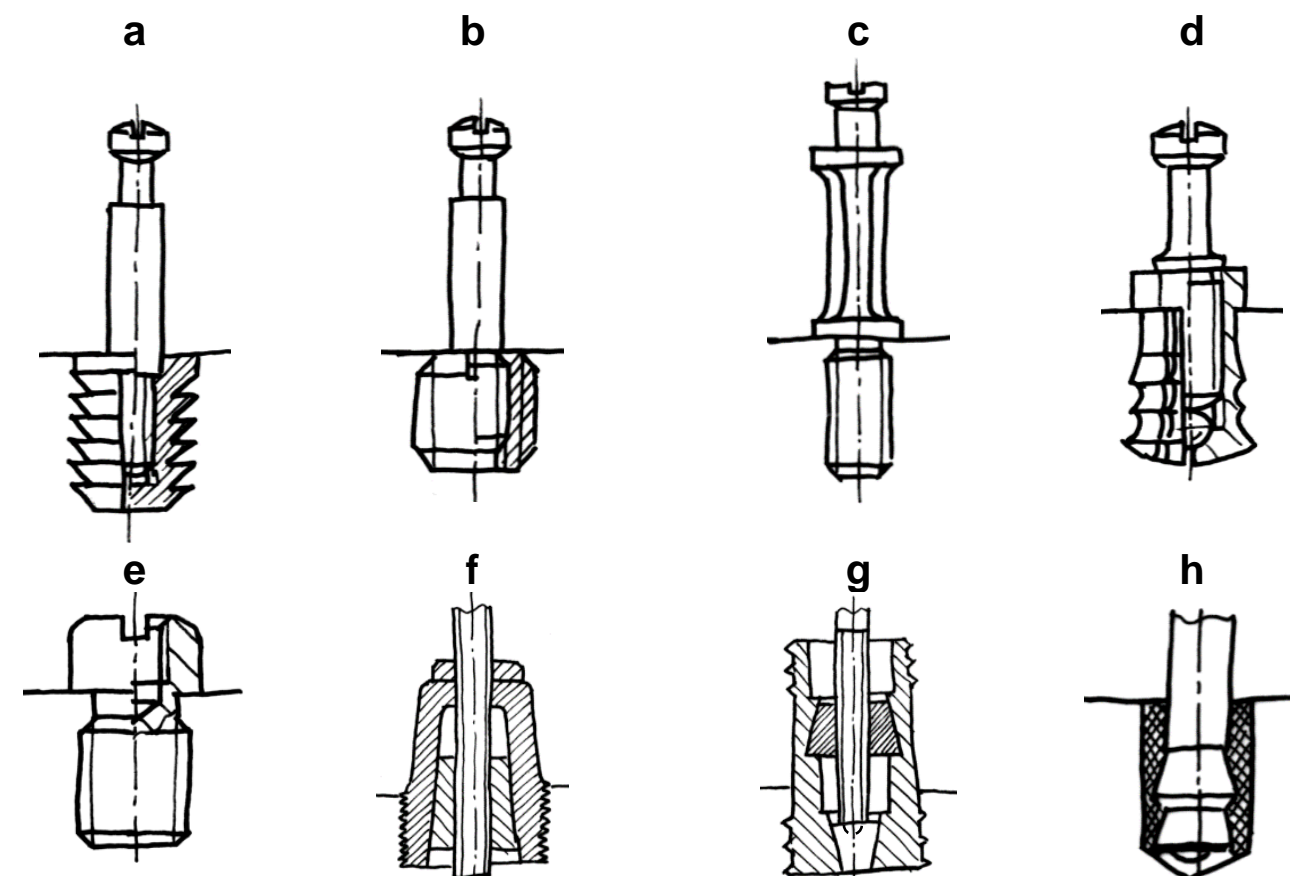

Fig. 2. Sample engineering designs of mandrels and couplers: a - mandrel with driven in
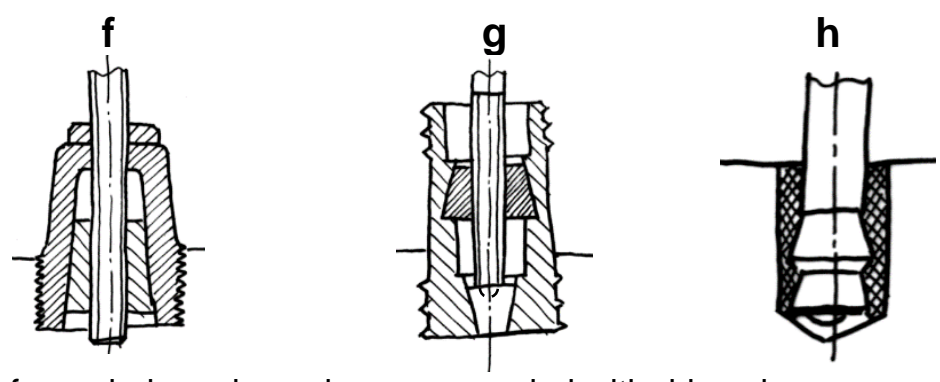
polyamide muff, b - mandrel with screwed in steel muff, c - directly screwed in mandrel, $\mathrm{d}$ - mandrel with brass coupler expanded by polyamide ball, e - screw connector of INVIS fastener, $f$ - threaded mandrel with a coupler expanding cone, $g$ - threaded mandrel with two coupler expanding cones, $\mathrm{h}$ - slidable mandrel with coupler expanding cones

Figure 2 presents some examples of engineering solutions of fastener anchoring systems in furniture. They provide connections with a strong local concentration of stress, connected with the transfer of forces from one joined element onto the other. The distribution of stresses is uneven along the length of the thread because of a very small elastic deformation of the threaded metal mandrel and nonuniform elastic deformation of the mounting sockets in the joined furniture panels made of foamed lignocellulosic fibrous composite (Sydor and Wieloch 2009; Sydor 2019; Chen et al. 2019). The material of the steel mandrel of the fastener (either extended or compressed) is much more rigid than the 
material of the lignocellulosic board; the concentration of load is at the end of the mandrel and increases with the increase in the $E_{t} / E_{k}$ ratio of the Young's modulus of the mandrel and the wood composite board (e.g., the $E_{t} / E_{k}$ ratio is approximal 75 for chipboard and approximal 20 for oakwood). Generation of the assembly clamping force (Fig. 2c, d, e) or initial radial compressive stresses by self-threading or tight-fitting fastening results in a welcome change to the distribution of load.

A polyamide ball, the principal function of which is to expand the coupler in the mounting socket (Fig. 2d) during the installation, exerts an axial force perpendicular to the end face of the mandrel, which favourably affects the distribution of load on the respective coils of the thread (an evener distribution). A screwed-in coupler with glue increases the extraction force many times over. Designs shown in Figs. $2 \mathrm{f}, 2 \mathrm{~g}$, and $2 \mathrm{~h}$ are commonly used in building construction anchoring systems. The two-cone solution can easily be used in expansion fastening of two panels of furniture at the same time.

\section{Methods of Tensioning and Adjusting Assembly Forces in Furniture Joints}

A fastener and joined furniture panels are subjected to a force necessary to ensure assembly clamping and furniture working load. The positioning and fixing the panels to be joined force is usually applied using a mechanism that is externally driven. The input of a rotary drive into the angular joint is positioned perpendicularly to the joint tensioning direction. Therefore, it needs an intersecting axis gear to translate the rotary motion of the drive (ROT - rotation) into mandrel travel (TRANS - translation). Table 2 presents commonly used types of fastener gear drives.

Table 2. The Main Types of Fastener Gear Drives

\begin{tabular}{|l|l|l|}
\hline & \multicolumn{1}{c|}{ Type of drive } \\
\hline ROT - ROT - TRANS \\
Toothed gear with spindle wheel - a helical gear with a coupler
\end{tabular}

Gear drives used in fasteners are self-locking devices thanks to the series connection of two gears: toothed and friction gear. The gear drives are characterized by:

- small wheel dimensions due to a small assembly opening of the pinion and wheel, 
fitting into a $10 \mathrm{~mm}$ (approx.) outline;

- the kinematic (not force-related) character of the rotational motion from the manual or mechanic screwdriver onto the screw;

- a lack of synchronised motion, which is typical of toothed gears. Interruptions in the motion are caused by a need to overcome some above standard inter-teeth play at the so-called contact ratio $\varepsilon<1$ (lack of cooperation between two pairs of pinion and wheel teeth during teeth engagement and disengagement);

- a small number of teeth (e.g., $\left.z_{1}=6, z_{2}=7\right)$ on the cooperating gears prevents the involute profile of engagement. A simplified cycloidal profile, crown gears and simplified engagement of a worm gear with helical teeth are used more frequently;

- reduced precision of manufacture and, most frequently, tooth contact of the cooperating gears, which limits the value of the transferred torque; also limiting the durability of the gear, which is not required in the furniture industry.

\section{Types of Fasteners Used in Practice}

Fasteners available on the market use different methods to ensure the assembly clamping force $\left(F_{\text {as }}\right)$. Cam fasteners (Fig. 3) are generally used in self-assembly furniture. Easy assembly - even for a non-professional end-user of furniture - and favorable prices contribute to their extensive use. Their main disadvantages include high visibility in the joint, lack of possibility to have them preassembled by the manufacturer, and high proneness to assembly errors (Branowski and Pohl 2004). Eccentric fasteners fulfill the partial functions of "TENSION" and "ENSURE" to a limited extent only.

a

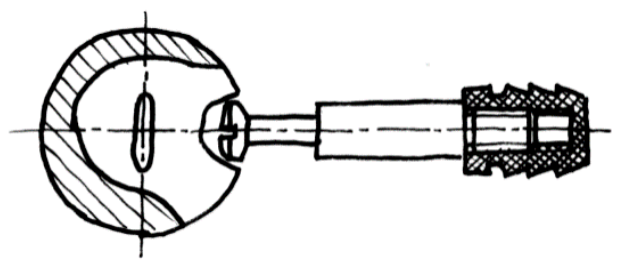

b
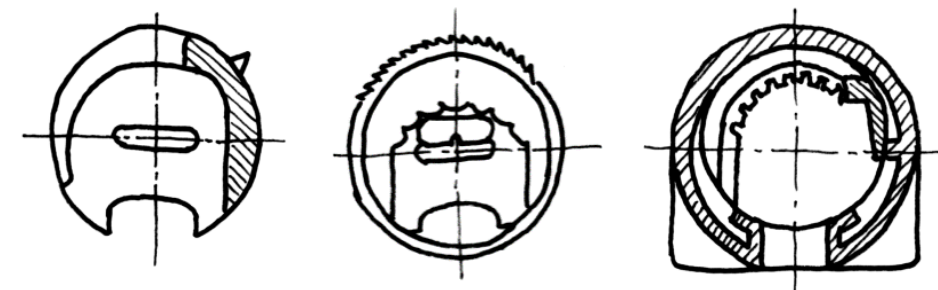

Fig. 3. Examples of cam fasteners: a - the view with mandrel and coupler, b - different design methods to secure the cam insert and mandrel against joint slackening

Figure 4 presents examples of fasteners with a gear drive (Fig. 4a and 4b), electromagnetic drive (Fig. 4c), and an innovative eccentric drive (Fig. 4d and 4e).

The fastener with bevel gear (Fig. 4a) features a unique combination of a slidable gear wheel (2) with screw (3), which makes the assembly with a coupler (5) easier, thanks to elastic support. Fasteners with toothed gears (Fig. $4 \mathrm{a}$ and $4 \mathrm{~b}$ ) feature metal bodies (4), divided and riveted once the fastener is assembled. Figure $4 \mathrm{c}$ shows a fastener featuring an electromagnetic drive, hardly ever used in the furniture industry, which makes the fastener almost invisible in the joint. In this case, the assembly force pressing together the joined 
components results from the action of an external rotating magnetic field onto a rotor (8) with permanent magnets (Fig. 4c). The rotation of the rotor is transferred onto the screw of the threaded insert via an impact clutch. When sound effects generated by the clutch cease, the joint tensioning process is finished, and the change of the direction of the external magnetic field allows one to disconnect the joint.
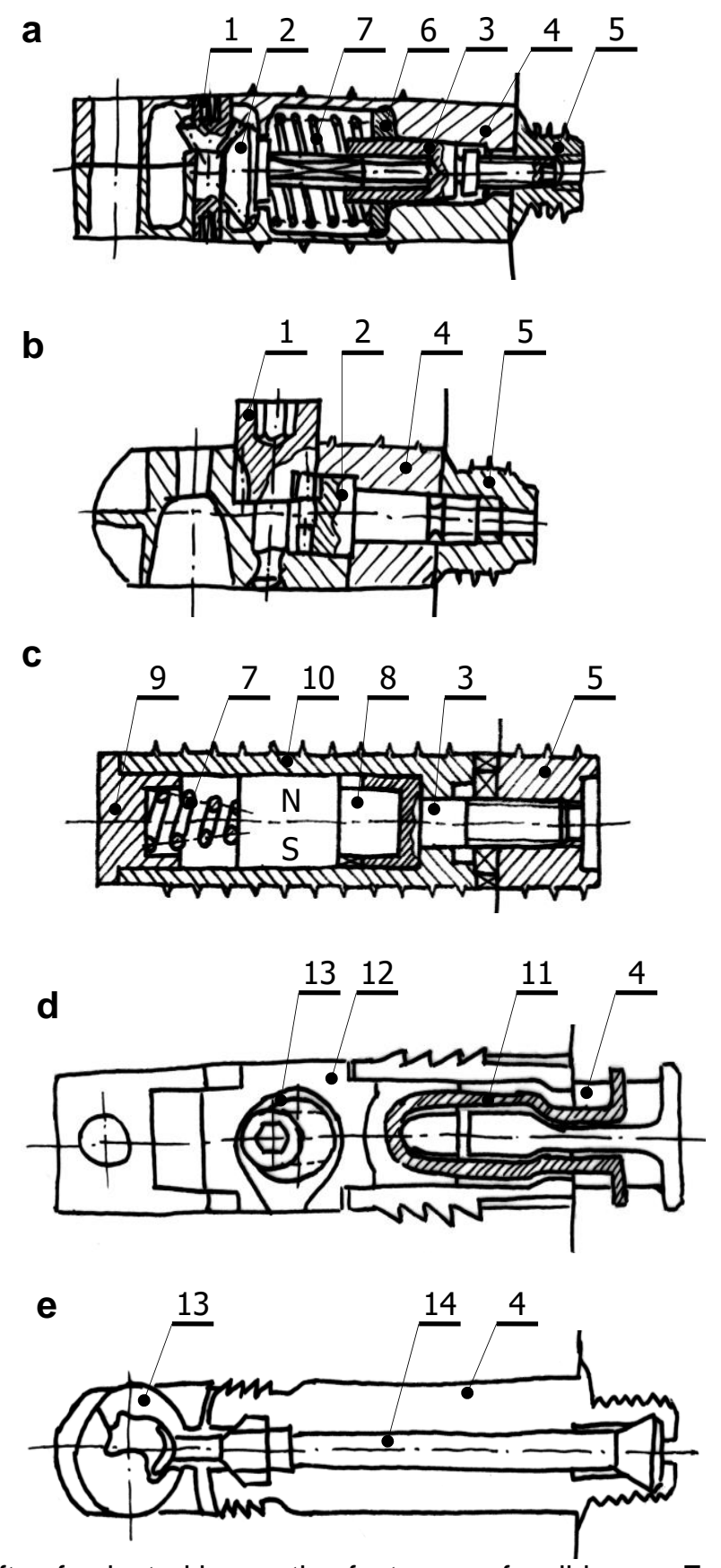

Fig. 4. Engineering drafts of selected innovative fasteners of well-known European companies: a - fastener with bevel gear by O.M.M. model GN501, b - fastener with crown gear by Italiana Ferramenta srl model target J10 (EP 2980423 B1), c - fastener with external drive by Lamello Verbindungstechnik $\mathrm{GmbH}$ model Invis Mx2 (magnet driven connecting fittings), $d$ - fastener with eccentric mechanism by Effegibrevetti (models: roto and rostro), e - fastener with cam mechanism by CAR srl BLU 12 with cone clamp (1 - pinion, 2 - gear wheel, 3 - screw, 4 - divided 
body, 5 - coupler, 6 - nut, 7 - spring, 8 - rotor, 9 - enclosure, 10 - body, 11 - elastic anchor, 12 anchor gear cluster, 13 - circular cam, 14 - mandrel)

In the fastener with a mandrel-eccentric mechanism (Fig. 4e), one eccentric drive (13) moves the mandrel (14) with wedge-shaped surfaces, expanding two surfaces anchoring the fastener's body in the joined panels. The plastic, divided body (4) has a plastic hinge and catches which close the body into one whole. In another metal fastener with an eccentric mechanism (Fig. 4d), an elastic anchor (11) opens out under the action of a circular cam-driven (13), anchor sliding change gear (12).

All engineering designs, shown in Figure 4, fit into a $\phi 13 \times 64 \mathrm{~mm}$ cylinder (most frequently $\phi 12 \times 50 \mathrm{~mm}$ ). They are manufactured using mass production technology usually with large dimensional tolerances, which translates itself into certain operational flaws. However, it ensures the competitiveness of the cost of manufacture and convenience of fastener assembly in the furniture.

\section{NOVEL, PROPRIETARY CONCEPTS AND ENGINEERING DESIGNS OF FASTENERS}

\section{Fastener Design Search Methodology}

The search for a solution to the fastener started with a need's identification (development of requirements) and an analysis of the current state of the art. Product design began by dividing the design issue into two subproblems (anchoring and drive). The search for a new concept was conducted by the small product development team. It was expected that because the organisation was small, creative discussions and a creative attitude of the team, and in particular the team leader, would boost new ideas. The team was to be a pillar of creative enthusiasm and belief in success. However, some typical differences in the creative commitment of the respective team members were present, resulting from their over-specialisation, fear of criticism, and desire to quickly apply ideas, as well as failed experiments and frequent changes to essential solutions. The joint-design process begins with the recognition and analysis of needs. This creates an initial object model, which is highly abstract, described by requirements. Defining and understanding the requirements is an essential precondition for the economic success of the designed object.

In product design methodology there are some requirements, called requests, which absolutely must be satisfied and other requirements, called wishes, which should be satisfied (Pahl and Beitz 1984; Branowski 1999; Cross 2008). The requirements for fasteners have been defined as follows:

- $\quad\left(R_{1}\right)$ user-friendly assembly of furniture fastener ((1) small number of assembly tools, (2) possible pre-assembly by the manufacturer, (3) only typical tools necessary, (4) small number of assembly operations, (5) convenient location of the mounting point, (6) short time of assembly, (7) small proneness to errors);

- $\quad\left(\mathrm{R}_{2}\right)$ friendly assembly of the fastener at the level of its mass production ((1) small number of parts (to be assembled), (2) number of assembly operations, (3) difficulty of assembly and time of assembly, (4) functional integration of parts);

- $\quad\left(\mathrm{R}_{3}\right)$ possibility to disconnect the joint for furniture disassembly or reconfiguration purposes ((1) proneness to damage at re-assembly, (2) number of operations for disassembly and assembly, (3) socket wear level);

- ( $\left.\mathrm{R}_{4}\right)$ fastener dimensions adjusted to the thickness $g$ of the joined panels ((1) external diameter $d<(0.75$ to 0.8$) g$, (2) depth of socket $h \leq d$, (3) $g_{\text {i dimensions in }}$ 
the horizontal and vertical panel, (4) possibility to use the fastener in boards thinner than $15 \mathrm{~mm}$ );

- $\left(\mathrm{R}_{5}\right)$ invisibility or low visibility of the fastener on the external furniture surfaces (partial visibility or invisibility) ((1) the fastener protrudes from the horizontal panel on the outside, (2) the fastener protrudes from the vertical panel on the inside, (3) level of visibility, (4) possibility to use a hole plug identical with the joined material when visible on the external furniture surfaces);

- (R6) embedding the fastener in a furniture component using a technologically secure frictional or shape-frictional joining method while maintaining self-locking (without adhesive connections);

- $\left(\mathrm{R}_{7}\right)$ obtaining considerable assembly clamping forces in the joined panels and the possibility of their adjustment (clamping force during assembly $F_{\text {as }}>60 \mathrm{~N}$ ),

- $\left(\mathrm{R}_{8}\right)$ transfer of considerable furniture working loads (in cooperation with the sidewall and pegs) in a quasi-elastic respect; elasticity of fastener tension (counteracting the relaxation phenomenon and advantageous for short-term loads occurring in fitted furniture);

- (R9) low costs of manufacture in mass production conditions ((1) number of components which need to be manufactured (non-standardized), (2) mass of components, (3) a large proportion of components manufactured using single-step methods (injection, extrusion));

- (R10) high fastener design quality ((1) aesthetics, (2) number of various elements for packing, (3) possibility to easily swap the setting elements when the joined elements are changed, (4) aesthetic packaging, (5) aesthetic appearance after application, (6) distinctive, unparalleled handling properties, (7) ergonomic grip during assembly) (8) customized to match the manufacturer's specificity;

- $\left(\mathrm{R}_{11}\right)$ minimal negative impact on the environment during production, use and recycling ((1) low energy consumption and emission during production, (2) biodegradability of materials, (3) number of used construction materials, (4) possibility to use recycled materials in production, (5) number of assembly operations, (6) opportunity for mass recycling);

- (R12) fastener innovativeness ((1) original design, (2) producibility of design, (3) patent, (4) European utility model, (5) awards (medals, diplomas, awards on international innovation shows);

- An additional design wish $\left(\mathrm{R}_{13}\right)$ is the possibility of repeated disassembly and reassembly of furniture with the applied fasteners, without the deterioration of the structural properties of the joint (anticipated number of assembly cycles without socket damage).

The subsequent team sessions produced several innovative fastener design ideas. The team members were blessed with an abundance of creativity - a psychological term describing a uniquely human feature manifesting itself as perception, intuition, and fluency in reasoning, which led to an excessive number of ideas that were difficult for the team to analyze critically. Therefore, it seemed only natural to adopt a trial and error approach and, through the success or failure of a modification of design concepts in terms of a fastener's material, form, structure, improved producibility and transfer of forces, arrive at a solution. Well-known inventive approaches were adopted: analogies to known objects, integration in combining the form and function of components, and adaptation to material changes of the joined panels. 


\section{Characteristics of the New Concepts and Designs of Fasteners}

After one year of work, the team produced over a dozen new concepts of fastener designs. Not all of them were brought into the phase of a working prototype due to manufacturing difficulties or unsuccessful application of the technology. Fastener tensioning and force adjustment drive during assembly were the basis of every new concept. Depending on the method of operation, all the developed innovative fastener designs have been categorized into seven groups and marked with symbols from S1 to S7. The S1 solution presented in Fig. 5 (granted patent (Starczewski 2019b)) features two racks (2 and 3) which are driven by a pinion (1). The racks have cones at their ends. These cones expand the muffs 4 and 5. The muff 5 is embedded in vertical panel P1, muff 4 is embedded in horizontal panel P2. There were issues with the development of a claw clutch inside the pinion (1) with the ability to release its lock at joint disconnection. Such a clutch is necessary because the fastener drive mechanism lacks self-locking properties. Unfortunately, with the required small dimensions of the pinion (71) (outside diameter of the gear approx. $5 \mathrm{~mm}$ ), no effective engineering solution to the mentioned clutch issue has been found.

a

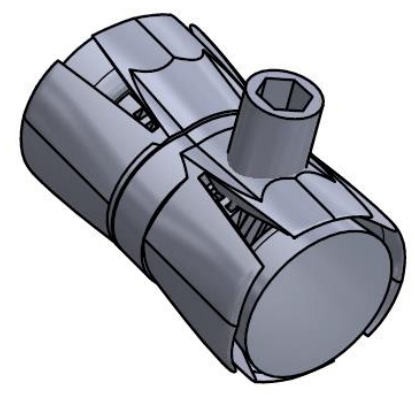

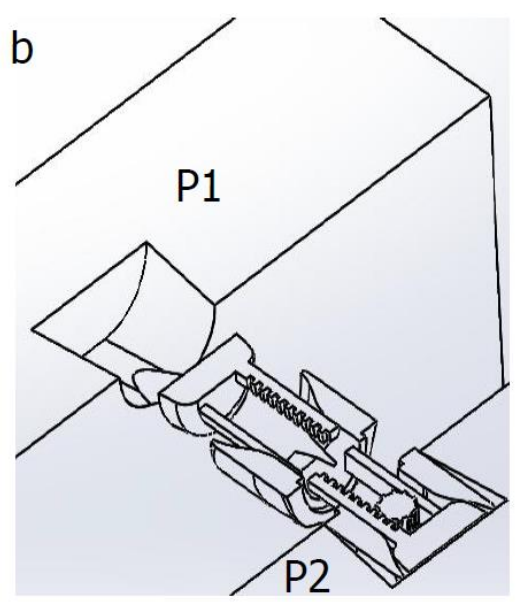

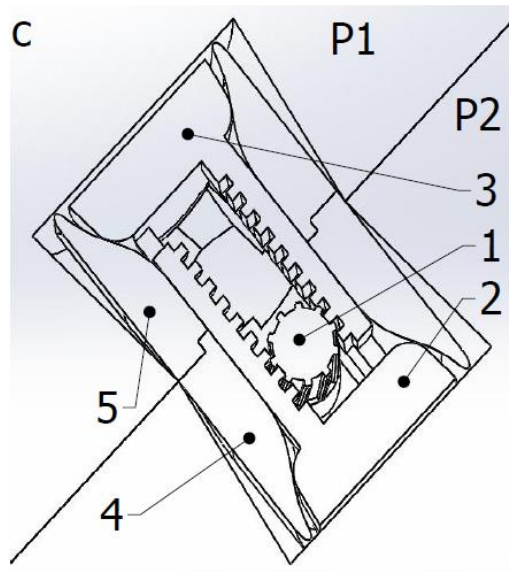

Fig. 5. Innovative fastener $S 1$ driven by a rack and pinion: a - view, b - exploited cross section, c cross section in joint (1 - pinion, 2 - rack $A, 3$ - rack $B, 4$ - expansion muff $A, 5$ - expansion muff $B$, P1 - vertical panel, P2 - horizontal panel) (based on Ref. (Starczewski 2019b))
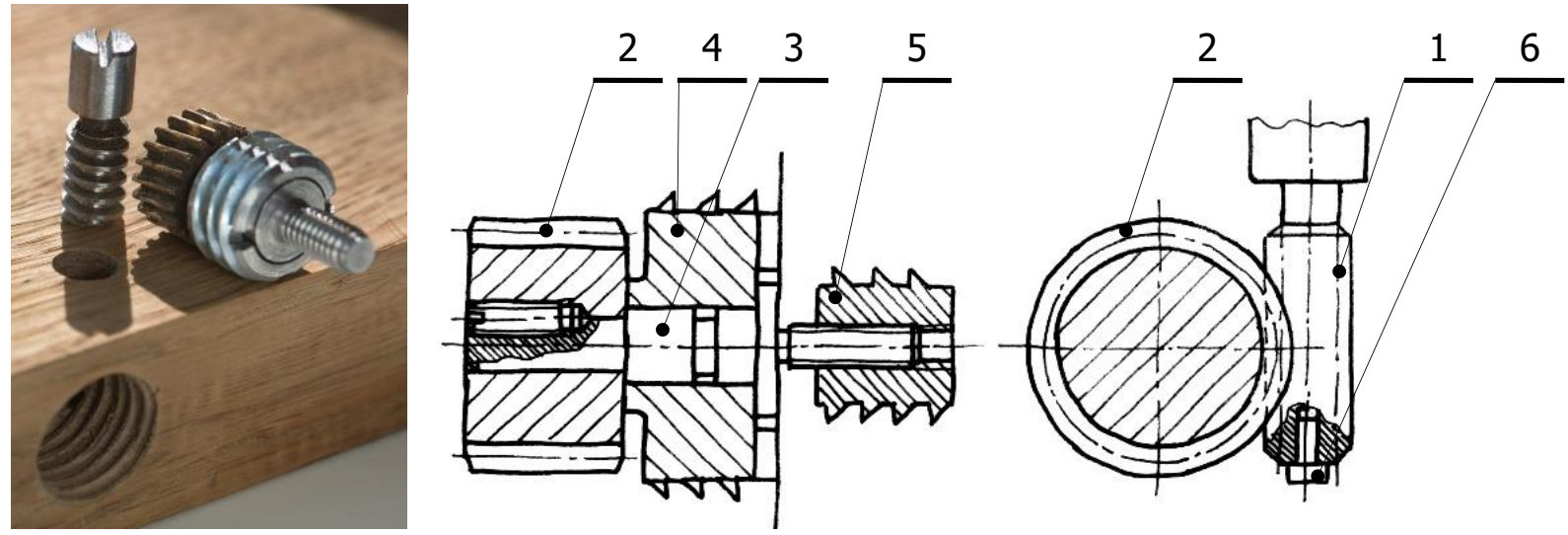

Fig. 6. Innovative fastener S2 based on a worm drive (1 - worm screw, 2 - worm wheel, 3 - axis of worm wheel, 4 - wheel bearing coupler, 5 - fastener coupler, 6 - worm bearing) 
The S2 solution with a worm drive presented in Fig. 6 features a steel worm screw (1), which drives a brass worm gear (2). The shaft of the worm wheel (3), with a threaded end, screws into the coupler of the fastener (5), generating the assembly clamping force on the joint. In the manufactured prototype with a worm gear and features given in Table 3 , the self-locking condition of the fastener drive is fulfilled.

Table 3. Characteristic Features of a Worm Gear

\begin{tabular}{|c|c|}
\hline Worm drive & Gear wheel \\
\hline Threading $Z \mathrm{~F}=1$, & Number of teeth $Z \mathrm{k}=20$ \\
\hline External diameter $d_{\mathrm{az}}=8 \mathrm{~mm}$ & External diameter $d_{\mathrm{ak}}=16.4 \mathrm{~mm}$ \\
\hline Module $\mathrm{m}_{\mathrm{n}}=0.63 \mathrm{~mm}$ & Module $m_{\mathrm{n}}=0.63 \mathrm{~mm}$ \\
\hline Flank angle $\alpha=20^{\circ}$ & Flank angle $\alpha=20^{\circ}$ \\
\hline Coil height $h_{\mathrm{z}}=1.4 \mathrm{~mm}$ & Teeth inclination angle $\beta=6.81^{\circ}$ \\
\hline- & Addendum modification coefficient $x=0.7$ \\
\hline \multicolumn{2}{|c|}{ Joint parameters: distance of axis $a=10.1 \mathrm{~mm}$; gear ratio $i=20$} \\
\hline
\end{tabular}

In the structural design, the worm screw is seated in the tip of a manual or mechanical screwdriver and is a part of the assembly tool, not a component of the fastener. The self-locking quality of the fastener results from the natural self-locking property of the threaded pair (5). A prototype of the fastener was made, and preliminary tests, consisting of joining two perpendicular furniture panels of thickness $g=30 \mathrm{~mm}$, were conducted. A fully functional joint was obtained, with a large force pressing down the joined panels, but the time of assembly was recognised as too long. It took over one minute to screw in five threads of the shaft ending into the coupler (100 rotations of the worm), and the assembly required putting intense pressure on the screwdriver against an axial force, pushing the worm out (equal to the circumferential force of the wheel). A screwdriver with the worm can be screwed out without changing the value of the assembly clamping force. Further development of the $\mathrm{S} 2$ concept requires a reconstruction of the bearing system and the use of a worm screw with a high thread inclination angle, so of a lower gear ratio at a higher efficiency, smaller number of teeth and worm wheel diameter.

Another concept, designated as S3, is shown in Fig. 7 (not filed with the patent office). This fastener can be used to connect panels in either a parallel or perpendicular way. The fastener drive has been designed in the form of a conical toothed gear ( 2 and 3 ), which drives a turnbuckle (4). The rotation of the screw moves the nuts (5 and 6) and they attract two connected panels to each other. A simulation of the movement of a conical gear, made using CAD software, shows that this particular design of the profile of teeth of conical wheels with the same number of teeth $z_{2}=z_{3}=7$ at small dimensions is hugely vulnerable to jamming when making small changes to the geometrical parameters of the teeth. Technological difficulties in the precise execution of teeth were the reason why the development of this concept was abandoned.

A fastener S4 shown in Fig. 8 (not submitted to the patent office) uses a dynamic, spring-actuated beater. The released potential energy of the spring (4), through the rotation of the pin (5), transfers kinetic energy onto the beater (3) with a spring (4) system. This energy, when the beater (3) hits a rod (1) with an expanding cone (6) generates friction when the rod (1) with the expanding cone (6) is moved into the body (2) and clamp of the anchoring element (P1), bringing together two connected furniture panels. The disadvantage is a unidirectional character of energy conversion in the fastener, making fastener disassembly impossible. 


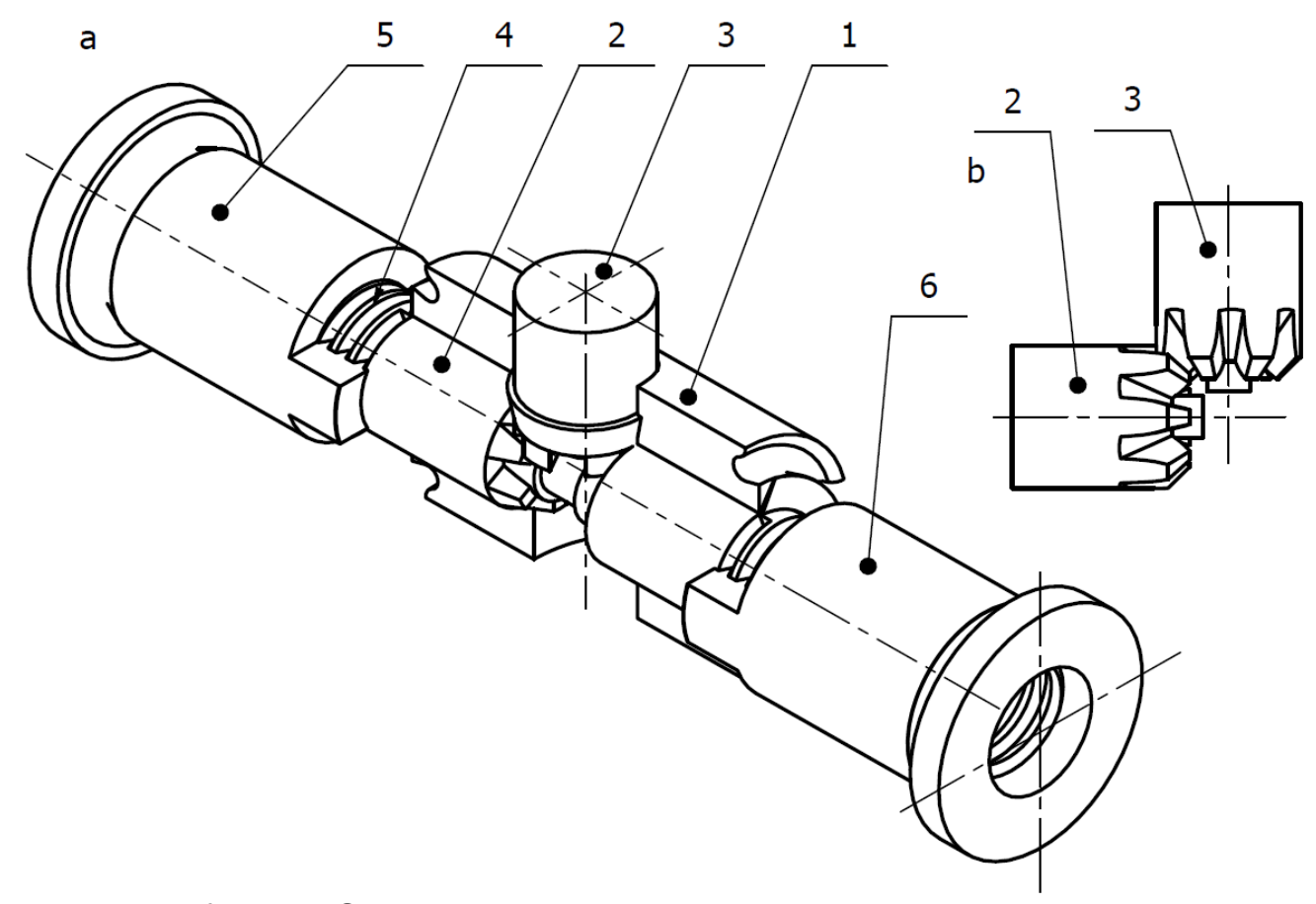

Fig. 7. Innovative fastener S3 with the conical toothed gear with turnbuckle mechanism and two nuts: a - view, b - gear (1 - body, 2 - driven gear, 3 - driving gear, 4 - turnbuckle, 5 - nut anchored in the face of first panel, 6 - nut anchored in the side of second panel)

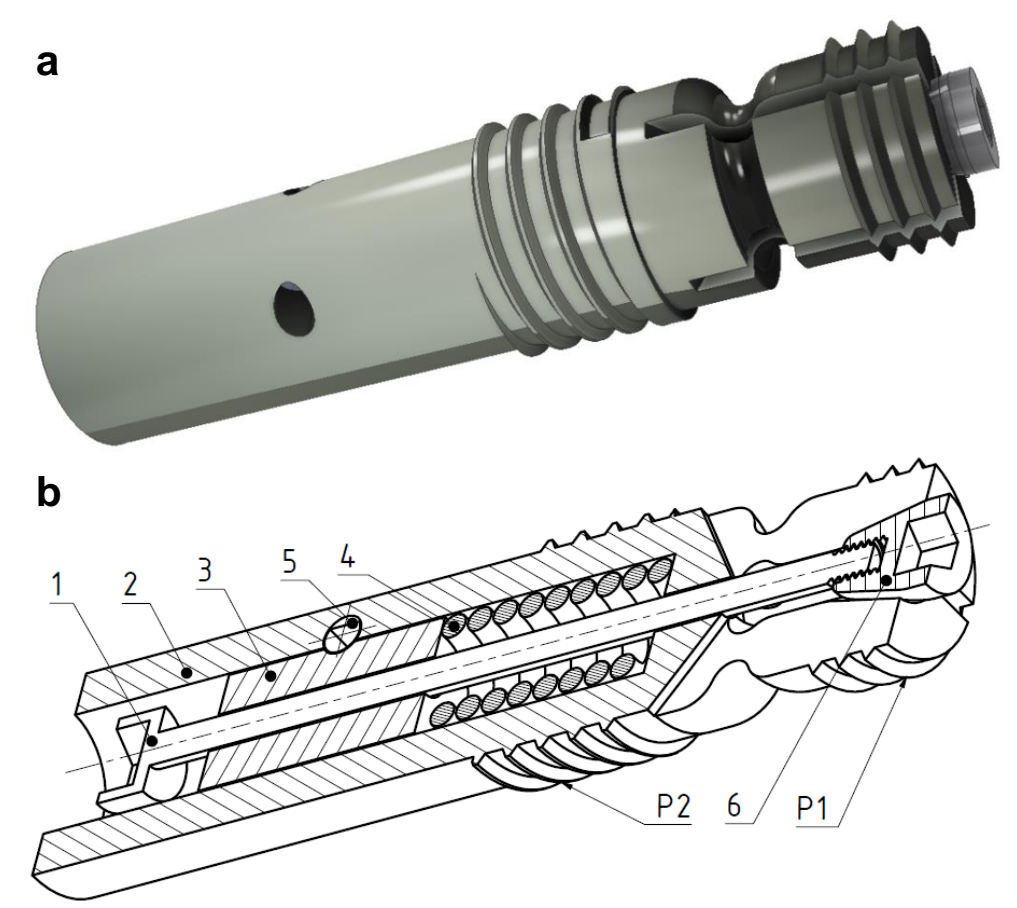

Fig. 8. Innovative fastener $S 4$ with a percussive beater spring drive to move the expanding cone: a - view, b - cross section (1 - rod, 2 - body, 3 - beater, 4 - spring, 5 - spring releasing pin, 6 expanding cone, P1 - body thread anchoring fastener in the vertical panel, P2 - body thread anchoring fastener in the horizontal panel) 
The fastener presented in Fig. 9 (design S5, not filed with the patent office) is based on a mechanism of a rotating disk with two spiral grooves (3), which drive slidable racks (4 and 5). The components of the fastener are made from a steel strip in various metalworking technologies (cutting, bending, stamping, embossing). The rack's movement, generated by the rotation of the disk (2), makes the anchoring elements (P1 and $\mathrm{P} 2$ ) expand through the expanding cams (B4 and B5). The mechanism is self-locking.

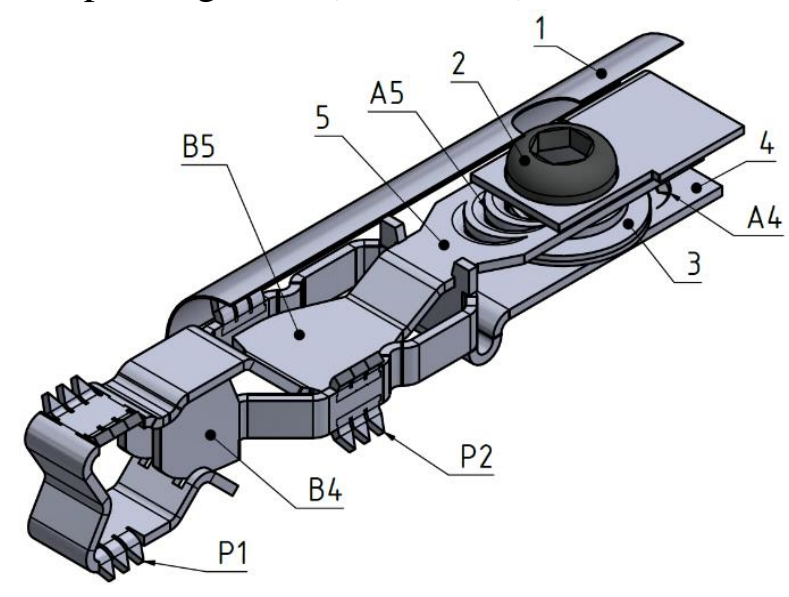

Fig. 9. Innovative fastener S5 based on a mechanism of a rotating disk with spiral cams at both sides (Archimedean spiral) driving the slidable racks (1 - body (partial view), 2 - drive element, 3 disk with spiral grooves, 4 - bottom rack, A4 - bottom rack spiral groove, B4 - bottom rack expansion element, 5 - upper rack, A5 - upper rack spiral groove, B5 - upper rack expansion element, P1 - anchoring teeth in the vertical panel, P2 - anchoring teeth in the horizontal panel)

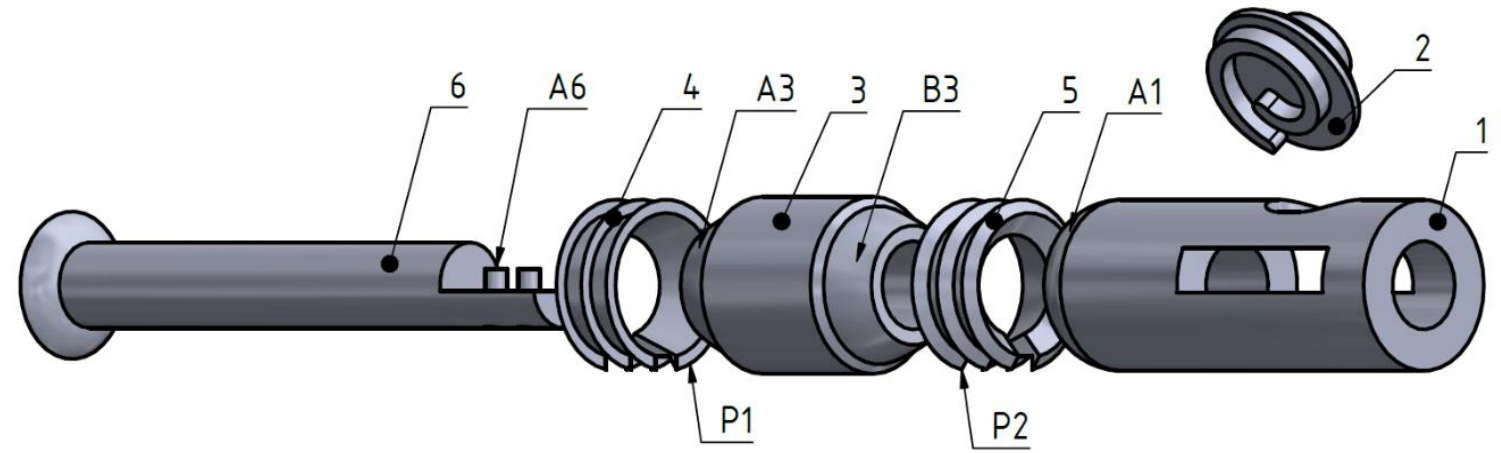

Fig. 10. Innovative fastener $S 6$ based on two anchoring rings, driven by a disk with a spiral drive (1 - body, 2 - disk with a spiral drive, 3 - biconical sleeve, A3 - cone expanding first anchoring ring, B3 - cone expanding second anchoring ring, 4 - first anchoring ring, 5 - second anchoring ring, 6 - mandrel, A6 - teeth driven by spiral drive, P1 - anchoring teeth in the vertical panel, P2 anchoring teeth in the horizontal panel)

The engineering design of fasteners presented in Figs. 10 and 11 was deemed the most successful from the whole group of design concepts (designs S6 and S7). The concept of the S6 fastener in Fig. 10 (Patent Application (Starczewski 2019a)) features a mechanism consisting of a rotating disk with a spiral drive (2) driving a mandrel (6). The mandrel moves the biconical sleeve (3), which in turn expands the anchoring elements (4 and 5) in the sockets made in joined panels.

A different principle of operation is used in the concept of fastener S7 from Fig. 11 (Patent Application (Branowski and Starczewski 2019)). In that concept, the driving screw (4) with a slidable nut makes four identical levers (7) turn around two supporting rollers (5 and 6). Forces on the ends of the levers act on a split expanding muff ( 2 and 3 ) from both 
sides of the fastener. When the fastener is closed, a force that generates assembly clamping is exerted on the panels P1 and P2.

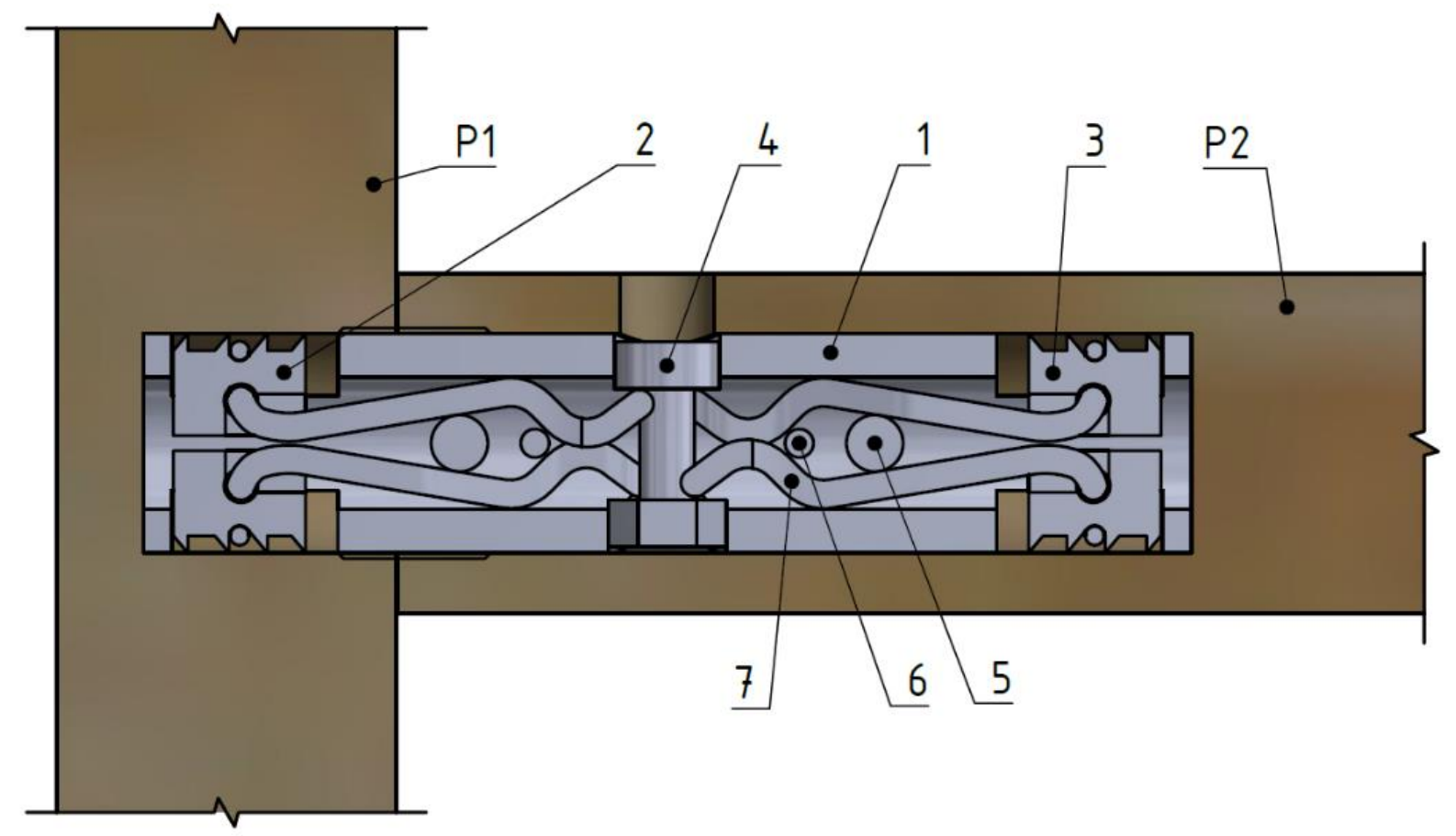

Fig. 11. Innovative fastener $S_{7}$ with four levers (1 - body, 2 - expansion muff in panel P1 (vertical), 3 - expansion muff in panel P2 (horizontal), 4 - driving screw, 5 - lever spreading pin, 6 - lever shifting pin, 7 - one of four levers, P1-P2 - fastened panels)

The presented group of seven engineering designs $\left\{R_{j}\right\} \mathrm{j}=1, \ldots 7$ is highly innovative. The radically new designs, which may in some cases be characterized as inventions, confirm this statement. The three described designs of fasteners S1, S6, and S7 were submitted to the Polish Patent Office as inventions (Branowski and Starczewski 2019; Starczewski 2019a; b). The creative uniqueness of the designs most often stems from the novelty of kinematic gears converting the rotary movement of the miniature angular helical gear (solutions S1, S2, S3). Because the cooperating wheels have a minimal number of teeth, atypical teeth profiles or (whenever classical involute profiles are used) increased inter-teeth play is required, which consequently causes the loss of a full synchronization of the gear ratio. In another group of designs S5, S6, the drive converts the rotary motion of a disk with an Archimedean spiral into rack movement. The self-locking travel of the rack activates elements, which anchor the fastener in the mounting sockets by their movement on the wedge-shaped surfaces in the S5 design or movement on the conical expanding surfaces in the S6 design. The specificity of the mechanisms which secure the fastener in the openings ensures the assembly clamping of the joined furniture panels. The new principles of performing the fastener function are applied in solutions S4 and S7. In the S4 design, a percussive beater driven by a spring screw drives a rod connected with a cone, expanding the body, which clamps the fastener in the opening. The S7 design uses levers driven by a bolt-nut gear. The structural form of the lever ensures the anchoring of the fastener in the mounting socket and assembly clamping of the joined panels. 
The paper presents only those fasteners of which the design process ended with a prototype. There were about 12 designs created at the conception and construction stage, some of which have been redesigned. This way, there were tens of design versions created. For example, design S6 had 12 options and design S7 - 5 options. The reason why multiple options of a particular engineering design $\left(S_{j}\right)$ were generated was the need for various technical, technological, and economic adjustments. The adjustments concerned: (1) geometric structural characteristics, (2) material properties, and (3) change of assembly features and formation of initial settings. Technological features were also of importance, for example, the number of technological operations, processing time, possibility to manufacture using mass production technology, and number of manual operations during assembly. The changes also resulted from a critical analysis of the designs, difficulties in the manufacture of prototypes, presence of prototypes that were unsuccessful in terms of functionality, unsatisfactory results of empirical research of joints made using the new fasteners.

\section{MULTI-CRITERIAL EVALUATION OF PROTOTYPES OF THE NEW FASTENERS}

The research produced a collection of seven different engineering designs of fasteners. Each one has its own known structural character and geometric, material, and dynamic structural features. All solutions within the set meet the requirements. The history of their development is known, as is the technical knowledge of the design concepts, structures, structural versions and prototypes.

The dilemma arises regarding which solutions should be selected for preparation for the further production process. Three inherent elements formulate this task: the set of solutions $\left\{S_{j}\right\}$, the set of requirements $\left\{R_{i}\right\}$ and a particular primary criterion of choice $K$ of a specified design $S_{j}$, evaluated as the best in terms of the adopted sub-criteria $k_{j}$ evaluation system.

The described new engineering designs of fasteners $\left\{S_{1}-S_{7}\right\}$ were subjected to criteria-based evaluation. It was assumed that the set of structural sub-criteria would consist of principal, in terms of their importance, already mentioned structural requirements $\left\{R_{i}\right\}$. Pairwise comparison was selected as the method for comparing requirements (according to (Branowski 1999; Cross 2008)). The classification table, in terms of requirement importance, is given in Tables 4 and 5. The more important requirements were marked in Tables 4 and 5 as (+), less critical as (-), and equally important as (0).

The thirteen-element group of requirements (point 3.1.) was rated using a pairwise comparison (Cross 2008). The group of requirements included both requests $\left(R_{1}, \ldots R_{12}\right)$ and a wish $R_{13}$. The evaluation was carried out based on the opinion of two, two-person, independent teams of experts in the field of precision engineering, mechanical engineering and wood technology. Tables 4 and 5 also include the average results of the importance coefficient determined in the ranking method. This ranking was then standardised into the $g_{\text {inorm }}$ classification based on the following relationship:

$$
g_{i \text { norm }}=\frac{g_{i}}{g_{i \max }}
$$


Table 4. Requirement Importance $R_{\mathrm{i}}$ Classification Table According to Mechanics Experts

\begin{tabular}{|c|c|c|c|c|c|c|c|c|c|c|c|c|c|c|c|c|}
\hline & 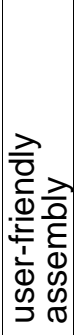 & 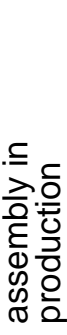 & 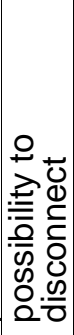 & 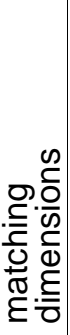 & 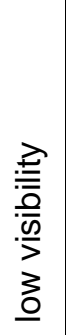 & 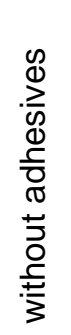 & 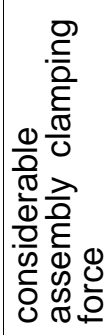 & 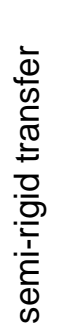 & 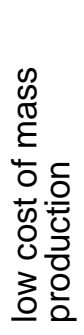 & 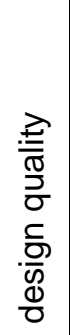 & 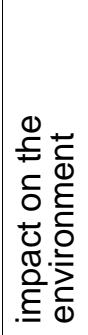 & 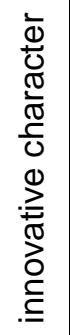 & 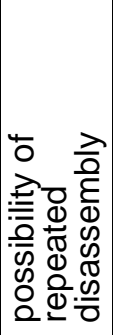 & 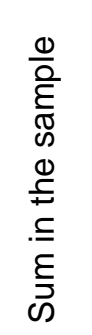 & 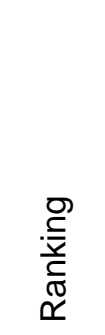 & 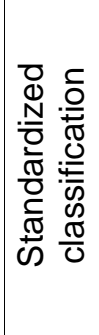 \\
\hline & $R_{1}$ & $R_{2}$ & $R_{3}$ & $R_{4}$ & $R_{5}$ & $R_{6}$ & $R_{7}$ & $R_{8}$ & $R_{9}$ & $R_{10}$ & $R_{11}$ & $R_{12}$ & $R_{13}$ & $\sum+_{(1)}$ & $g_{i}[\%]$ & $g_{\text {inorm }}$ \\
\hline$R_{1}$ & & + & + & 0 & + & - & + & - & - & + & + & + & + & 8 & 11.11 & 0.67 \\
\hline$R_{2}$ & - & & - & - & - & - & 0 & - & - & + & - & + & - & 2 & 2.78 & 0.17 \\
\hline$R_{3}$ & - & + & & 0 & - & - & - & - & - & + & - & - & + & 3 & 4.17 & 0.25 \\
\hline$R_{4}$ & 0 & + & 0 & & + & + & + & - & - & + & + & + & + & 8 & 11.11 & 0.67 \\
\hline$R_{5}$ & - & + & + & - & & + & - & - & - & + & 0 & + & + & 6 & 8.33 & 0.50 \\
\hline$R_{6}$ & + & + & + & - & - & & - & - & - & + & - & + & + & 6 & 8.33 & 0.50 \\
\hline$R_{7}$ & - & 0 & + & - & + & + & & + & - & + & + & + & + & 8 & 11.11 & 0.67 \\
\hline$R_{8}$ & + & + & + & + & + & + & - & & - & + & + & + & + & 10 & 13.88 & 0.83 \\
\hline$R_{9}$ & + & + & + & + & + & + & + & + & & + & + & + & + & 12 & 16.67 & 1.00 \\
\hline$R_{10}$ & - & - & - & - & - & - & - & - & - & & - & - & - & 0 & 0 & 0 \\
\hline$R_{11}$ & - & + & + & - & 0 & + & - & - & - & + & & 0 & 0 & 4 & 5.56 & 0.33 \\
\hline$R_{12}$ & - & - & + & - & - & - & - & - & - & + & 0 & & + & 3 & 4.17 & 0.25 \\
\hline$R_{13}$ & - & + & - & - & - & - & - & - & - & + & 0 & - & & 2 & 2.78 & 0.17 \\
\hline & & & & & & & & & & & & & & 72 & $100 \%$ & \\
\hline
\end{tabular}

Note: "+" - more important requirements, "“" - less critical requirements, "0" - equally important requirements

Based on the evaluation of the importance coefficients, only seven requirements were selected for further analysis (Table 6). The requirements of fastener aesthetics $R_{10}$, user-friendly assembly $R_{2}$, possibility to disconnect $R_{3}$ and impact on the environment $\mathrm{R}_{11}$ were disregarded because their importance was negligible or because of difficulties in modelling at the preliminary design stage. Those difficulties resulted from the fact that no model furniture with the fasteners, pins, and back wall exists. It was concluded that the innovativeness requirement $\mathrm{R}_{12}$ and the repeated assembly requirement $R_{13}$ would not constitute criteria because of the low rating obtained over the course of the study.

The requirements used in the next step of the fastener design evaluation and selection process were the requirements left after the selection, treated as structural subcriteria. It should be noted that publications on the methodology of technical design (Pahl and Beitz 1984; Tarnowski 1997) usually mention structural criteria as the main criteria. These sub-criteria are of the highest importance for the accuracy of the design development process. After reducing the number of criteria, those left are structured as follows: $R_{l}$ (userfriendly assembly), $\mathrm{R}_{4}$ (dimensions matching board thickness), $R_{5}$ (low visibility), $R_{6}$ (frictional or shape embedding in the board), $R_{7}$ (defined assembly clamping force), $R_{8}$ (correct transfer of working loads), $R_{9}$ (low costs). The weight coefficients $w_{i}$ of sub-criteria $R_{i}$ should be rescaled for this set (Table 6). This way, a new hierarchy of the importance of criteria is created, with the $\mathrm{R}_{9}$ criterion, the fastener cost criterion, as of the highest importance. 
Table 5. Requirement Importance $R_{\mathrm{i}}$ Classification Table According to Furniture Technology Experts

\begin{tabular}{|c|c|c|c|c|c|c|c|c|c|c|c|c|c|c|c|c|}
\hline & 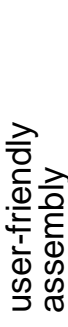 & 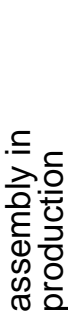 & 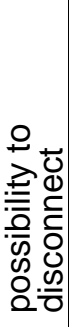 & 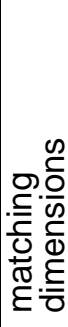 & 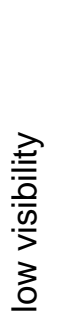 & 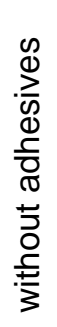 & 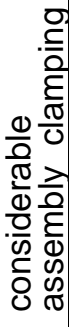 & 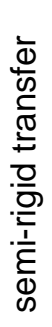 & 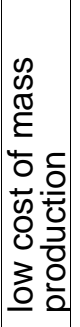 & 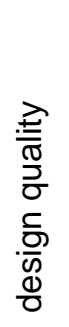 & 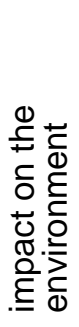 & 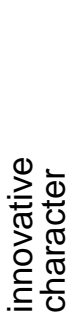 & 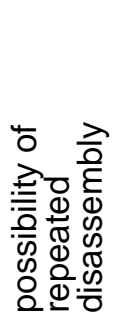 & 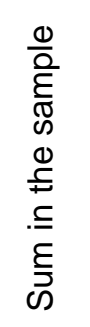 & 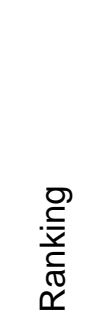 & 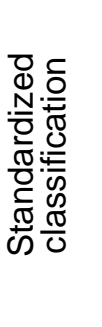 \\
\hline & $R_{1}$ & $R_{2}$ & $R_{3}$ & $R_{4}$ & $R_{5}$ & $R_{6}$ & $R_{7}$ & $R_{8}$ & $R_{9}$ & $R_{10}$ & $R_{11}$ & $R_{12}$ & $R_{13}$ & $\Sigma+_{(2)}$ & $g_{i}[\%]$ & $g_{i \text { norm }}$ \\
\hline$R_{1}$ & & + & + & + & + & - & - & + & - & + & + & + & + & 9 & 12.00 & 0.82 \\
\hline$R_{2}$ & - & & - & - & - & - & - & - & - & - & - & - & - & 0 & 0 & 0 \\
\hline$R_{3}$ & - & + & & - & - & - & - & - & - & + & + & - & + & 4 & 5.33 & 0.36 \\
\hline$R_{4}$ & - & + & + & & + & - & - & - & - & + & + & - & + & 6 & 8.00 & 0.55 \\
\hline$R_{5}$ & - & + & + & - & & - & - & - & - & + & + & + & + & 6 & 8.00 & 0.55 \\
\hline$R_{6}$ & + & + & + & + & + & & - & + & 0 & + & + & + & + & 10 & 13.33 & 0.91 \\
\hline$R_{7}$ & + & + & + & + & + & + & & + & 0 & + & + & + & + & 11 & 14.67 & 1.00 \\
\hline$R_{8}$ & - & + & + & + & + & - & - & & - & + & + & + & + & 8 & 10.67 & 0.73 \\
\hline$R_{9}$ & + & + & + & + & + & 0 & 0 & + & & + & + & + & + & 10 & 13.33 & 0.91 \\
\hline$R_{10}$ & - & + & - & - & - & - & - & - & - & & - & - & - & 1 & 1.33 & 0.09 \\
\hline$R_{11}$ & - & + & - & - & - & - & - & - & - & + & & - & 0 & 2 & 2.67 & 0.18 \\
\hline$R_{12}$ & - & + & + & + & - & - & - & - & - & + & + & & + & 6 & 8.00 & 0.55 \\
\hline$R_{13}$ & - & + & - & - & - & - & - & - & - & + & 0 & - & & 2 & 2.67 & 0.18 \\
\hline & & & & & & & & & & & & & & 75 & 100 & \\
\hline
\end{tabular}

Note: "+" - more important requirements, "-“ - less critical requirements, "0" - equally important requirements

Table 6. Rescaling of Weight Coefficients $W_{\mathrm{i}}$ with the Selection of Sub-criteria $R_{\mathrm{i}}$

\begin{tabular}{|c|c|c|c|c|c|c|c|c|c|c|c|c|c|}
\hline Criteria $R_{i}$ & $R_{1}$ & $R_{2}$ & $R_{3}$ & $R_{4}$ & $R_{5}$ & $R_{6}$ & $R_{7}$ & $R_{8}$ & $R_{9}$ & $R_{10}$ & $R_{11}$ & $R_{12}$ & $R_{13}$ \\
\hline$\sum+_{\mathrm{a}}=\frac{\sum+_{(1)}+\sum+_{(2)}}{2}$ for $R_{i}$ & 8.5 & 1.0 & 3.5 & 7 & 6 & 8 & 9.5 & 9 & 11 & 0.5 & 3 & 4.5 & 2 \\
\hline$W_{p}$ & 0.14 & - & - & 0.12 & 0.10 & 0.14 & 0.16 & 0.15 & 0.19 & - & - & - & - \\
\hline $\begin{array}{l}\text { Note: the sum of the selected criteria comparisons - criteria } \Sigma+_{\mathrm{a}} \text { for }\left\{R_{i}\right\} \text { equals } 59 \text {, and the } \\
\text { weight } W_{p}=R_{i} / \Sigma+_{\mathrm{a}}=1.00\end{array}$ \\
\hline
\end{tabular}

The issue of the selection of designs $\left\{S_{j}\right\}(\mathrm{j}=1,2, . ., 7)$, in regard to the adopted criteria value system $\left\{R_{i}\right\}$, is based on the following assumptions. A linear decision-making strategy on the hierarchy of the choice of the $S_{j}$ solution design and the independence of the evaluation criteria were assumed. This strategy compensates for the shortage and excess of values represented by the respective sub-criteria. The form of the solution selection criterion $K$ is as follows: $K=\sum^{p} w_{p} \cdot k_{p}$, where $w_{p}$ is the weight coefficient of criterion $R_{i}$, and $k_{p}$ is the point value of engineering design $S_{j}$ for sub-criterion $R_{i}$.

A five-point scale, according to guidelines Verein Deutscher Ingenieure (VDI 2225. 1998; VDI 2225 1998), typically used in product value analysis, was adopted in the study. In this scale, the recommended point values of sub-criteria are: 0 - unsatisfactory design, 1 - bearable design, 2 - sufficient design, 3 - good design, 4 - very good (ideal) 
design. This gradation of scores shows that it is only possible to estimate the design versions because of scarce knowledge about the properties of the individual designs. The gradation can be described using simple evaluative judgements: 0 - much lower than the average, 1 - lower than the average, 2 - average, 3 - above average, 4 - much more above average. In these assessments the score 2.5 corresponds to the average. It should be pointed out that a very good design (score 4) is the ideal design, meaning that all scores should be extremal, maximal. This protocol is challenging to follow when a set of seven criteria is considered.

The partial scores and the results of fastener evaluation are presented in Table 7. The S7 engineering design, with the screw-lever drive pressing down elements joined by the lever's cams (Fig. 11), is considered to be the best proprietary fastener design. Fastener design S6 with the linear drive expanding the conical mechanisms (Fig. 10) is also good. Two other designs, S3 and S4, are only slightly less advantageous.

Table 7. Evaluation of solutions $S_{\mathrm{j}}$

\begin{tabular}{|c|c|c|c|c|c|c|c|c|c|c|c|c|c|c|c|}
\hline & & \multicolumn{2}{|c|}{ S1 } & \multicolumn{2}{|c|}{ S2 } & \multicolumn{2}{|c|}{ S3 } & \multicolumn{2}{|c|}{ S4 } & \multicolumn{2}{|c|}{ S5 } & \multicolumn{2}{|c|}{ S6 } & \multicolumn{2}{|c|}{ S7 } \\
\hline & $\begin{array}{l}k_{p} \\
\text { pts. }\end{array}$ & $\mathrm{k}_{\mathrm{p}(1)}$ & $\mathrm{k}_{\mathrm{p}(2)}$ & $\mathrm{k}_{\mathrm{p}(1)}$ & $k_{p(2)}$ & $\mathrm{k}_{\mathrm{p}(1)}$ & $k_{p(2)}$ & \begin{tabular}{l|}
$k_{p(1)}$ \\
\end{tabular} & $\mathrm{k}_{\mathrm{p}(2)}$ & $k_{p(1)}$ & $\mathrm{k}_{\mathrm{p}(2)}$ & $k_{p(1)}$ & $\mathrm{k}_{\mathrm{p}(2)}$ & $\mathrm{k}_{\mathrm{p}(1)}$ & $k_{p(2)}$ \\
\hline \multirow{2}{*}{$R_{1}$} & $k_{p}$ & 1 & 1 & 1 & 1 & 1 & 4 & 3 & 4 & 1 & 4 & 3 & 4 & 3 & 4 \\
\hline & $w_{p}$ & \multicolumn{14}{|c|}{0.14} \\
\hline \multirow{2}{*}{$R_{4}$} & $k_{p}$ & 3 & 2 & 1 & 1 & 3 & 4 & \begin{tabular}{|l|}
3 \\
\end{tabular} & 3 & 3 & 4 & 3 & 4 & 3 & 4 \\
\hline & $w_{p}$ & \multicolumn{14}{|c|}{0.12} \\
\hline \multirow{2}{*}{$R_{5}$} & $k_{p}$ & 3 & 3 & 2 & 3 & 2 & 3 & 3 & 4 & 2 & 3 & 3 & 3 & 3 & 3 \\
\hline & $w_{p}$ & \multicolumn{14}{|c|}{0.10} \\
\hline \multirow{2}{*}{$R_{6}$} & $k_{p}$ & 1 & 4 & 2 & 4 & 4 & 4 & 2 & 4 & 1 & 4 & 2 & 4 & 3 & 4 \\
\hline & $w_{p}$ & \multicolumn{14}{|c|}{0.14} \\
\hline \multirow{2}{*}{$R_{7}$} & $k_{p}$ & 0 & 4 & 4 & 4 & 4 & 4 & \begin{tabular}{l|l}
1 \\
\end{tabular} & 3 & 2 & 2 & 3 & 3 & 2 & 4 \\
\hline & $w_{p}$ & \multicolumn{14}{|c|}{0.16} \\
\hline \multirow{2}{*}{$R_{8}$} & $k_{p}$ & 0 & 3 & 3 & 3 & 3 & 4 & \begin{tabular}{l|l}
3 \\
\end{tabular} & 3 & 2 & 3 & 3 & 3 & 4 & 4 \\
\hline & $w_{p}$ & \multicolumn{14}{|c|}{0.15} \\
\hline \multirow{2}{*}{$R_{9}$} & $k_{p}$ & 1 & 1 & 1 & 1 & 1 & 1 & 2 & 3 & 3 & 2 & 3 & 3 & 4 & 4 \\
\hline & $w_{p}$ & \multicolumn{14}{|c|}{0.19} \\
\hline & Ki & 1.13 & 2.52 & 2.02 & 2.40 & 2.54 & 3.33 & 2.35 & 3.38 & 2.03 & 3.05 & 2.86 & 3.40 & 3.18 & 3.90 \\
\hline \multicolumn{2}{|c|}{$\begin{array}{c}\text { average } \\
K=0.5 \\
\left(K_{(1)}+K_{(2)}\right)\end{array}$} & \multicolumn{2}{|c|}{1.83} & \multicolumn{2}{|c|}{2.21} & \multicolumn{2}{|c|}{2.94} & \multicolumn{2}{|c|}{2.87} & \multicolumn{2}{|c|}{2.54} & \multicolumn{2}{|c|}{3.13} & \multicolumn{2}{|c|}{3.54} \\
\hline
\end{tabular}

\section{ANALYSIS OF RESULTS AND DISCUSSION}

A needs analysis of the fasteners' requirements makes it possible to define their two internal systems: a system anchoring the fastener in the boards and a drive system to exert the assembly clamping force. For each system, it is possible to make a classification according to specific operative engineering structures. There were eight engineering structures identified in the anchoring system, differentiated by the physical principles of their operation (Tab. 1). The choice of the type of fastener to be fixed in a furniture element depends mainly on the material properties of the wood composite board. There were thirteen types of fittings and mechanisms identified in the drive system exerting the board clamping force and transferring the furniture working loads, including: four drive systems with a toothed gear and a crossed helical gear, two drive systems with an eccentric gear, 
three fittings with a trapezoid ferrule and four drives with gears with different principles of operation.

The primary source of difficulties in the design the drive system exerting the assembly clamping force is the small geometrical dimension of fasteners, forcing the use of small mechanisms, and requiring a non-classical approach to the design process. What makes them stand out is a frequent lack of continuity in the transmission of power and tiny dimensions of gear wheel teeth, with teeth profiles and quantities unparalleled in other fields of technology. This has been confirmed by structural analyses of selected innovative and mass-produced modern fasteners of considerable structural complexity. They showed that fasteners of a complex, multi-element structure are expensive to produce and their cost is several times higher than the cost of eccentric fasteners, which are more commonly used in the furniture industry.

Problems connected with the miniaturisation of the drive elements are a major technological issue. For example, during the construction of the physical prototype of our own fastener design, based on the rotary cam mechanism with an Archimedean spiral driving the rack, the miniaturisation of parts generated a difficulty in obtaining the right printing quality in the SLA 3D printing method using titanium powders (Figs. 12 and 13). The millimetre measure shown in the pictures helps to get a feel of the original size of the object. The quality was considerably improved when the cam manufacturing method was changed in favour of machining (Fig. 14).
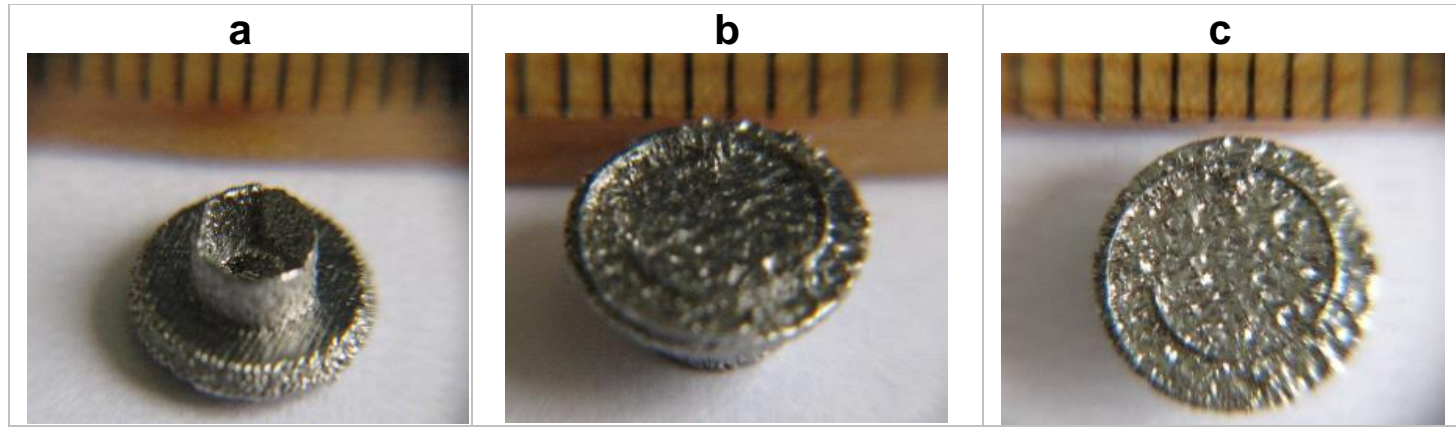

Fig. 12. Rotary cam with a spiral made using the 3D SLA printing method from titanium powder: a - view from the top, $b$ - element with the Archimedean spiral in isometry, $c$ - view from the bottom (the millimetre gradation scale is shown in the top part of the picture)

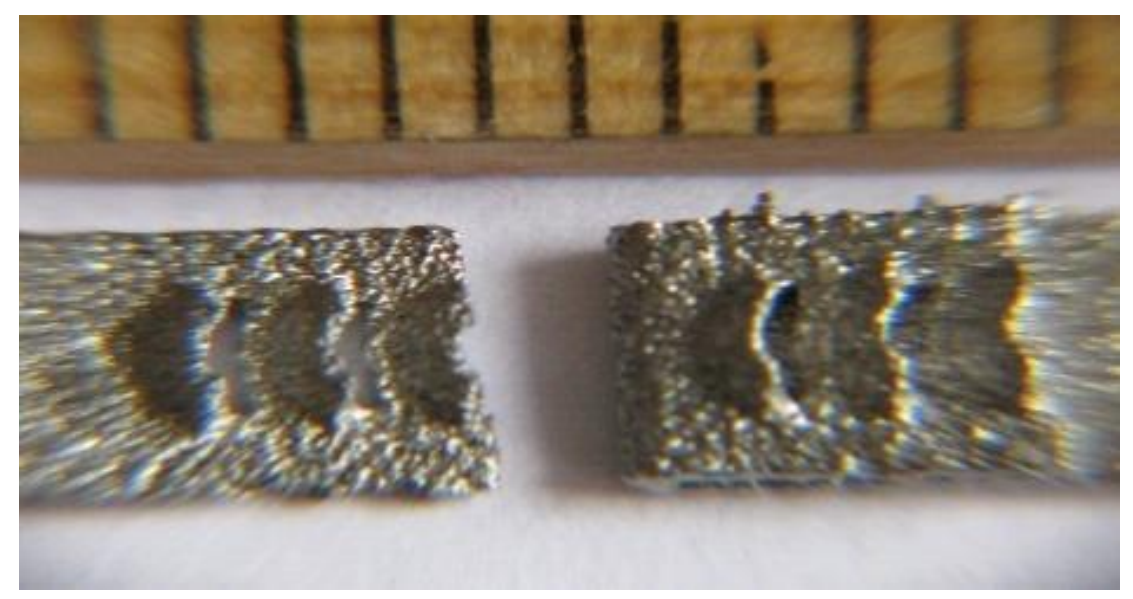

Fig. 13. Fastener's rack made using the 3D SLA printing method from titanium powder (note: the millimetre gradation scale is shown in the top part of the picture) 


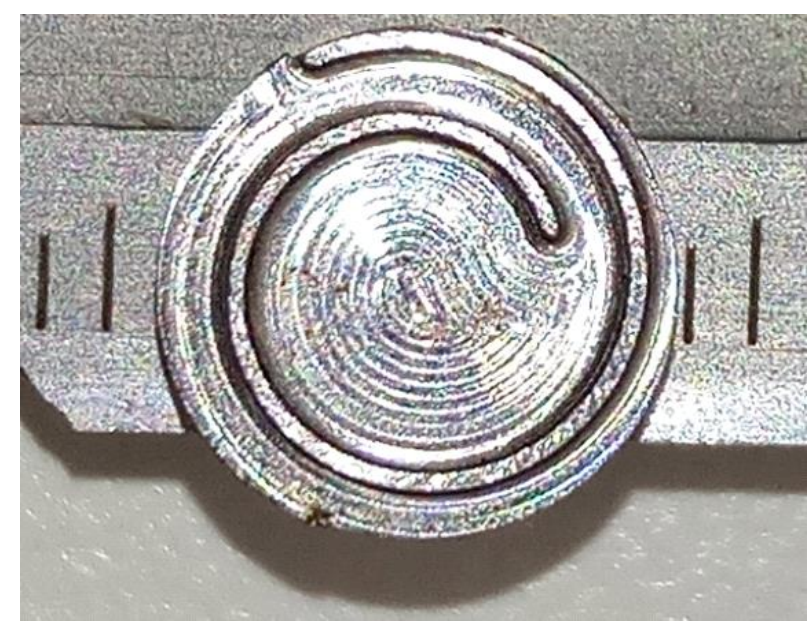

Fig. 14. Rotary cam with a spiral made by machining processes (note: the millimetre gradation scale is shown behind the cam)

Stringent restrictions on the overall dimensions of the fastener (length and diameter) result from the limited thickness of the joined panels. For this reason, the operation of a slidable rack drive via rotary cam with a spiral was analysed on a fifteentimes enlarged physical model made from wood composites and transparent plexiglass (Fig. 15). The model presented in Fig. 15 made it possible to verify the correct operation of the innovative fastener drive.

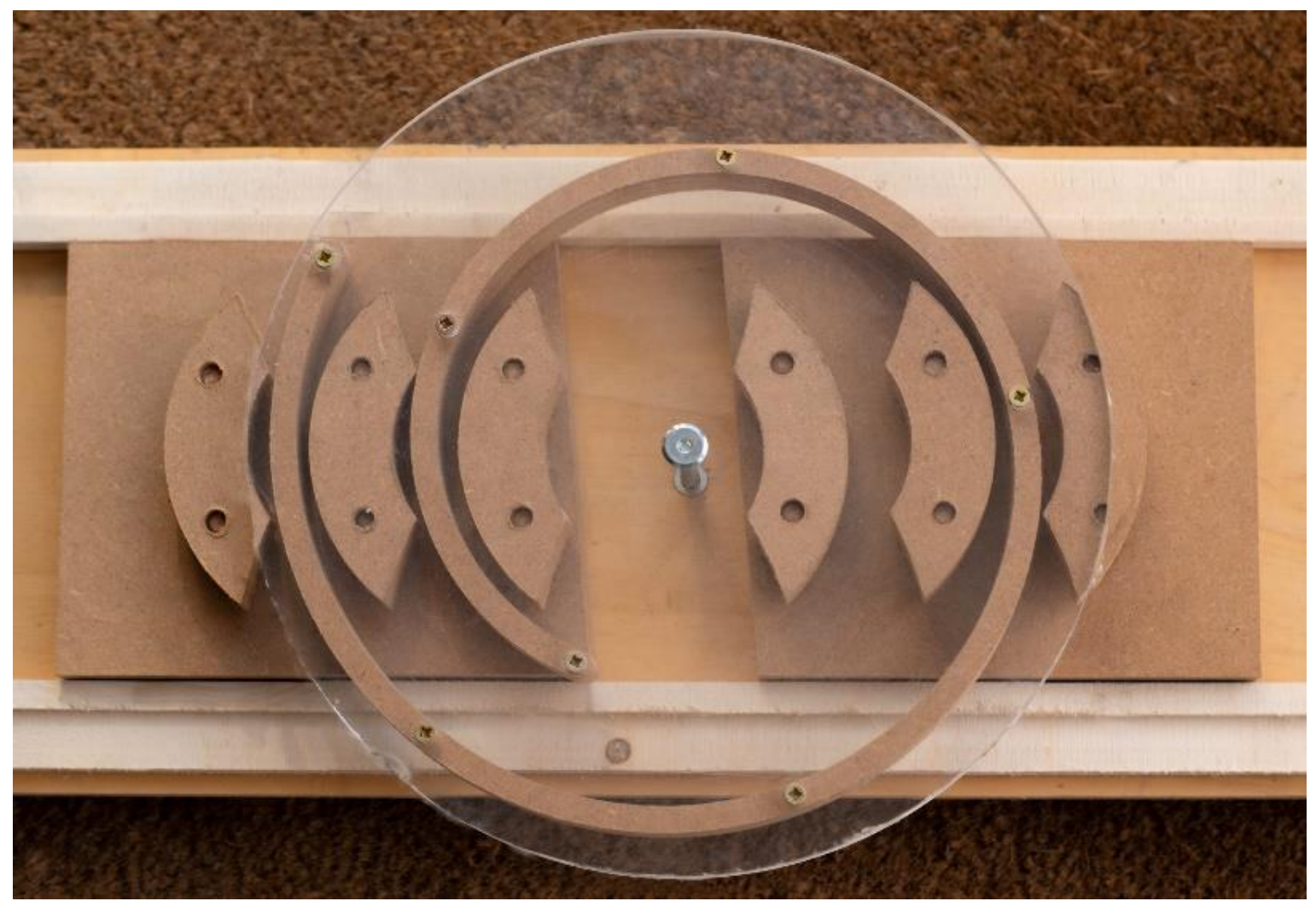

Fig. 15. Larger scale model of a slidable rack driven via rotary cam with a spiral (15 times enlarged) 
According to Altshuller's theory (TRIZ), all innovations emerge from the application of a very small number of inventive strategies, and technology evolution trends are highly predictable (Altshuller and Shapiro 1956; Mann 2001; Terninko et al. 1998). Therefore, it is possible to apply a methodical approach to solving complex design issues. The methodical approach to new product design was summarised and developed by Pahl and Beitz in 1977 (Pahl and Beitz 1977) and complemented and extended in further studies (e.g. systematic design method (Weiss and Hari 2015)). They consider the issue of obtaining an optimal engineering design as a two-way relationship: project team, manufacturer and product on one side, and the unknown user on the other side.

\section{OBSERVATIONS AND CONCLUSIONS}

Fasteners for RTA furniture are important in the development of modern furniture technology. Flat pack "frameless" furniture optimize small spaces in houses due to their dismantling properties. Moreover, growing consumer preference for customization feature in home furnishing drives the manufacturers to develop these products. When designing fasteners, three elements must be reconciled: a furniture manufacturer, a fastener manufacturer, and a customer buying furniture for self-assembly. A greater difficulty is the complex and ambiguous design properties of furniture lignocellulosic boards. That is why designing a fastener with favorable features is so difficult.

Seven new, original engineering designs of fasteners, patent-protected in three cases, were developed and described in the article. These furniture fasteners were subjected to evaluation and choice to find a solution that is the best in terms of the adopted criteria. The particular importance of each structural criterion was identified, and the set of requirements was reduced to essential requirements. They form a set of structural subcriteria. Through the prism of those sub-criteria, having specified weight coefficients, their hierarchy was determined, and some perspective designs were selected. The selected variants of fasteners would give the basis for technical prototypes, the implementation of changes resulting from the prototyping process and then implementation into production.

Based on the implementation of the described activities, the following observations and conclusions can be formulated:

1. All furniture fasteners can be broken down into two subsystems: the system to anchoring the fastener in the panels and the drive system to exert the assembly force.

2. There is a relatively small variety of anchoring systems and a slightly bigger variety of drive systems. Only two types of fastener anchoring systems and four drive systems used in practice were found to be suitable in state-of-the-art analysis.

It can be also stated:

- Small dimensions of the steel gears and the need to transfer large loads lead to the need for a few number of teeth in the each wheels $(z=6)$. The teeth profiles are simplified, and the significant play results in noncontinuous gear operation. Experience from other fields of technology (construction of precise mechanisms) cannot be directly applied in the construction of fasteners because all small module toothed elements used in those fields of technology would have insufficient strength. Another limitation results from the necessity to ensure the self-locking function of the fastener mechanism (a one-way drive). A positive feature is that the fastener drive does not have to work continuously for a long time and is only 
expected to execute a few assembly and disassembly cycles.

- The presented process of designing new furniture fasteners can be generalised. It allows one to creatively solve other engineering issues, in which it is necessary to find a three-element relationship: product $\rightarrow$ manufacturer $\rightarrow$ unknown product user. The recommended method of conduct is as follows: (a) identification of needs, methodical analysis of the state of the art and general description of the future product in the form of requirements, (b) breaking down the functionality of the designed product, (c) development of variants and feasibility study, (d) multicriterial evaluation of variants, (e) building prototypes and conducting functionaltechnological verification, (f) implementation in production.

- The design process, described in the article, is an exemplification of the "Digital twins" (in sense of (Tao et al. 2018)) of physical objects (prototypes of fasteners) and their virtual representations (CAD models, which are the proxy for images of the fastener in the minds of the design team).

\section{ACKNOWLEDGMENTS}

The paper presents the partial results of a European project taking part in the Polish sectoral programme WoodINN implemented by the National Centre for Research and Development (NCRD) within Operational Programme Smart Growth 2014-2020. Designation and title of the project: POIR.01.02.00-00-00102/17 "The first Polish innovative universal system of furniture fasteners for joining various wood and woodcomposite materials in the furniture industry".

\section{AUTHOR STATEMENT}

BB: Conceptualization, Methodology, Validation, Supervision. KS: Visualization, Project administration, Funding acquisition. MZ: Investigation, Data Curation, Visualization. MS: Methodology, Resources, Writing - Original Draft, Writing - Review \& Editing, Visualization.

\section{REFERENCES CITED}

Altshuller, G. S., and Shapiro, R. G. (1956). “О психологии изобретательского творчества / On the psychology of inventive creation," Вопросы Психологии / Psychology Issues 6, 37-49.

Asimow, M. (1962). Introduction to Design, Prentice-Hall, Englewood Cliffs, NJ, USA.

Bartashevich, A., and Trofimov, S. (2006). Конструирование Мебели / Furniture Design. Учебная литература для ВУЗов / Educational literature for universities, Современная школа / Modern school, Minsk, Belarus.

Branowski, B. (1999). Metody Twórczego Rozwiązywania Problemów Technicznych / Methods of Creative Solving of Engineering Problems, Wielkopolska Korporacja Techniczna NOT, Poznań, Poland.

Branowski, B., and Murawski, K. (2003a). "Samohamowne złącze kątowe / Self-locking angular connection [PL 353223 A1]," Patent Office of the Republic of Poland. 
Branowski, B., and Murawski, K. (2003b). "Kątowe złącze rozbieralne / Angular separable coupling [PL 206675 B1]," Patent Office of the Republic of Poland.

Branowski, B., and Pohl, P. (Eds.). (2004). Modelowanie Pótsztywnych Węzłów Konstrukcyjnych Mebli / Modeling of Semi-rigid Furniture Joints, Wydawnictwo Akademii Rolniczej im. Augusta Cieszkowskiego, Poznań, Poland.

Branowski, B., and Starczewski, K. (2019). "[Patent application] Złącze meblowe / Furniture fastener [PL 430046 A1]," Patent Office of the Republic of Poland.

Branowski, B., Zabłocki, M., and Sydor, M. (2018). "Experimental analysis of new furniture joints," BioResources 13(1), 370-382. DOI: 10.15376/biores.13.1.370-382

Chen, M., Li, S., and Lyu, J. (2019). "Effects of selected joint parameters on tensile strength of steel bolt-nut connections in Cupressus funebris wood," BioResources 14(3), 5188-5211. DOI: 10.15376/biores.14.3.5188-5211

Cross, N. (2008). Engineering Design Methods. Strategies for Product Design, John Wiley \& Sons, NJ, USA.

Eckelman, C. A. (1978). Strength Design of Furniture, Purdue University, West Lafayette, IN, USA.

Hitka, M., Joščák, P., Langová, N., Krišt’ák, L., and Blašková, S. (2018). "Load-carrying capacity and the size of chair joints determined for users with a higher body weight," BioResources 13(3), 6428-6443. DOI: 10.15376/biores.13.3.6428-6443

Joščák, P. (2000). Pevnostné Navrhovanie Nábytku / Strength Design of Furniture, Technická univerzita vo Zvolene, Zvolen, Slovakia.

Joščák, P., and Langová, N. (2018). Pevnostné Navrhovanie Nábytku / Strength Design of Furniture, Technická univerzita vo Zvolene, Zvolen, Slovakia.

Langova, N., Réh, R., Igaz, R., Krišt’ák, L., Hitka, M., and Joščák, P. (2019). "Construction of wood-based lamella for increased load on seating furniture," Forests 10(525). DOI: 10.3390/f10060525

Máchová, E., Langová, N., Réh, R., Joščák, P., Krišt’ák, L., Holouš, Z., Igaz, R., and Hitka, M. (2019). "Effect of moisture content on the load carrying capacity and stiffness of corner wood-based and plastic joints," BioResources 14(4), 8640-8655. DOI: 10.15376/biores. 14.4.8640-8655

Mann, D. (2001). "An introduction to TRIZ: The theory of inventive problem solving," Creativity and Innovation Management 10(2), 123-125.

Pahl, G., and Beitz, W. (1977). Konstruktionslehre: Handbuch für Studium und Praxis, Springer Verlag, Berlin, Germany.

Pahl, G., and Beitz, W. (1984). Nauka Konstruowania / Konstruktionslehre: Handbuch für Studium und Praxis, (A. Walczak, tran.), Wydawnictwa Naukowo-Techniczne, Warszawa, Poland.

Podskarbi, M., Smardzewski, J., Moliński, K., and Molińska-Glura, M. (2016). "Design methodology of new furniture joints," Wood Industry/Drvna Industrija, 67(4). DOI: 10.5552/drind.2016.1622

Smardzewski, J. (2015). Furniture Design, Springer International Publishing AG, Basel, Switzerland. DOI: 10.1007/978-3-319-19533-9.

Smardzewski, J., Rzepa, B., and Kıliç, H. (2016). "Mechanical properties of externally invisible furniture joints made of wood-based composites," BioResources 11(1), 1224-1239. DOI: 10.15376/biores.11.1.1224-1239

Starczewski, K. (2019a). "[Patent application] Złącze meblowe / Furniture fastener [PL 430044 A1]," Patent Office of the Republic of Poland.

Starczewski, K. (2019b). "[Patent] Złącze meblowe / Furniture fastener [Pat.233254]," 
Patent Office of the Republic of Poland.

Sydor, M. (2005). Właściwości Konstrukcyjne Pótsztywnych Kątowych Połączeń Płyt Drewnopochodnych ze Złaczami [Design Features of semirigid Furniture Corner Joints with Fasteners], Ph.D. Dissertation, Politechnika Poznańska, WMRiT, Poznań, Poland. DOI: 10.13140/2.1.3231.7768

Sydor, M. (2018). "Innowacje w łączeniu mebli skrzyniowych. Analiza techniczna wybranych łączników / Innovations in cabinet furniture fastening. Technical analysis of selected connectors," Fastener. Rynek elementów złącznych, - (2/2018), 24-30.

Sydor, M. (2019). "Geometry of wood screws: A patent review," European Journal of Wood and Wood Products, 77(1), 93-103. DOI: 10.1007/s00107-018-1362-4

Sydor, M., and Wieloch, G. (2009). "Construction properties of wood taken into consideration in engineering practice," Drewno. Prace Naukowe. Doniesienia. Komunikaty 52(181), 63-73.

Taguchi, G. (1993). Taguchi on Robust Technology Development: Bringing Quality Engineering Upstream, ASME Press, NJ, USA.

Tao, F., Cheng, J., Qi, Q., Zhang, M., Zhang, H., and Sui, F. (2018). "Digital twin-driven product design, manufacturing and service with big data," The International Journal of Advanced Manufacturing Technology 94(9), 3563-3576. DOI: 10.1007/s00170017-0233-1

Tarnowski, W. (1997). Podstawy Projektowania Technicznego / Fundamentals of Engineering Design, Wspomaganie komputerowe CAD/CAM, Wydawnictwa Naukowo-Techniczne, Poland.

Terninko, J., Zusman, A., and Zlotin, B. (1998). Systematic Innovation: An Introduction to TRIZ (Theory of Inventive Problem Solving), Taylor \& Francis Ltd / CRC Press, London, United Kingdom.

VDI 2225 (1998). "Design engineering methodics. Engineering design at optimum cost Simplified calculation of costs," Verlag des Vereins Deutscher Ingenieure, Düsseldorf, Germany.

VDI 2225 (1998). "Design engineering methodics. Tables for engineering design at optimum cost," Verlag des Vereins Deutscher Ingenieure. Düsseldorf.

Weiss, M. P., and Hari, A. (2015). "Extension of the Pahl \& Beitz systematic method for conceptual design of a new product," Procedia CIRP 36, 254-260. DOI: 10.1016/j.procir.2015.03.010

Zwicky, F. (1967). "The morphological approach to discovery, invention, research and construction," in: New Methods of Thought and Procedure. Contributions to the Symposium on Methodologies, F. Zwicky and A. G. Wilson (eds.), Springer, New York, pp. 273-297.

Article submitted: August 14, 2020; Peer review completed: September 13, 2020;

Revised version received and accepted: September 16, 2020; Published: September 23, 2020.

DOI: $10.15376 /$ biores.15.4.8472-8495 